Atmos. Chem. Phys., 10, 3875-3890, 2010

www.atmos-chem-phys.net/10/3875/2010/

(C) Author(s) 2010. This work is distributed under

the Creative Commons Attribution 3.0 License.

\title{
Effects of relative humidity on aerosol light scattering in the Arctic
}

\author{
P. Zieger ${ }^{1}$, R. Fierz-Schmidhauser ${ }^{1}$, M. Gysel ${ }^{1}$, J. Ström ${ }^{2}$, S. Henne ${ }^{3}$, K. E. Yttri ${ }^{4}$, U. Baltensperger ${ }^{1}$, and \\ E. Weingartner ${ }^{1}$ \\ ${ }^{1}$ Paul Scherrer Institut, Laboratory of Atmospheric Chemistry, 5232 Villigen, Switzerland \\ ${ }^{2}$ Norwegian Polar Institute, Polarmiljøsenteret, 9296 Troms $\varnothing$, Norway \\ ${ }^{3}$ Empa, Laboratory for Air Pollution and Environmental Technology, Überlandstrasse 129, 8600 Dübendorf, Switzerland \\ ${ }^{4}$ Norwegian Institute for Air Research, Dept. Atmospheric and Climate Research, P.O. Box 100, 2027 Kjeller, Norway
}

Received: 15 December 2009 - Published in Atmos. Chem. Phys. Discuss.: 9 February 2010

Revised: 7 April 2010 - Accepted: 18 April 2010 - Published: 27 April 2010

\begin{abstract}
Aerosol particles experience hygroscopic growth in the ambient atmosphere. Their optical properties - especially the aerosol light scattering - are therefore strongly dependent on the ambient relative humidity (RH). In-situ light scattering measurements of long-term observations are usually performed under dry conditions $(\mathrm{RH}<30-40 \%)$. The knowledge of this RH effect is of eminent importance for climate forcing calculations or for the comparison of remote sensing with in-situ measurements. This study combines measurements and model calculations to describe the RH effect on aerosol light scattering for the first time for aerosol particles present in summer and fall in the high Arctic. For this purpose, a field campaign was carried out from July to October 2008 at the Zeppelin station in Ny-Ålesund, Svalbard. The aerosol light scattering coefficient $\sigma_{\mathrm{sp}}(\lambda)$ was measured at three distinct wavelengths $(\lambda=450,550$, and $700 \mathrm{~nm})$ at dry and at various, predefined RH conditions between $20 \%$ and $95 \%$ with a recently developed humidified nephelometer (WetNeph) and with a second nephelometer measuring at dry conditions with an average $\mathrm{RH}<10 \%$ (DryNeph). In addition, the aerosol size distribution and the aerosol absorption coefficient were measured. The scattering enhancement factor $f(\mathrm{RH}, \lambda)$ is the key parameter to describe the $\mathrm{RH}$ effect on $\sigma_{\mathrm{sp}}(\lambda)$ and is defined as the RH dependent $\sigma_{\mathrm{sp}}(\mathrm{RH}, \lambda)$ divided by the corresponding dry $\sigma_{\mathrm{sp}}\left(\mathrm{RH}_{\mathrm{dry}}, \lambda\right)$. During our campaign the average $f(\mathrm{RH}=85 \%, \lambda=550 \mathrm{~nm})$ was $3.24 \pm 0.63$ (mean \pm standard deviation), and no clear wavelength dependence of $f(\mathrm{RH}, \lambda)$ was observed. This means that the ambient scattering coefficients at $\mathrm{RH}=85 \%$ were on average about three times higher than the dry mea-
\end{abstract}

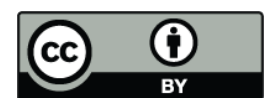

Correspondence to: E. Weingartner (ernest.weingartner@psi.ch) sured in-situ scattering coefficients. The RH dependency of the recorded $f(\mathrm{RH}, \lambda)$ can be well described by an empirical one-parameter equation. We used a simplified method to retrieve an apparent hygroscopic growth factor $g(\mathrm{RH})$, defined as the aerosol particle diameter at a certain RH divided by the dry diameter, using the WetNeph, the DryNeph, the aerosol size distribution measurements and Mie theory. With this approach we found, on average, $g(\mathrm{RH}=85 \%)$ values to be $1.61 \pm 0.12$ (mean \pm standard deviation). No clear seasonal shift of $f(\mathrm{RH}, \lambda)$ was observed during the 3-month period, while aerosol properties (size and chemical composition) clearly changed with time. While the beginning of the campaign was mainly characterized by smaller and less hygroscopic particles, the end was dominated by larger and more hygroscopic particles. This suggests that compensating effects of hygroscopicity and size determined the temporal stability of $f(\mathrm{RH}, \lambda)$. During sea salt influenced periods, distinct deliquescence transitions were observed. At the end we present a method on how to transfer the dry in-situ measured aerosol scattering coefficients to ambient values for the aerosol measured during summer and fall at this location.

\section{Introduction}

Continuous measurements of aerosol properties in the field, such as the wavelength dependent aerosol light scattering coefficient, are often performed under dry conditions (relative humidity $\mathrm{RH}<30-40 \%$ as recommended by $\mathrm{WMO} / \mathrm{GAW}$, 2003). These measurements at low RH can differ from the ambient conditions and thus may not be climatically relevant. Since ambient aerosol particles experience hygroscopic growth, their optical properties are strongly dependent on

Published by Copernicus Publications on behalf of the European Geosciences Union. 
$\mathrm{RH}$. The response of an ambient particle to $\mathrm{RH}$ depends mainly on the size and the solubility of the particle. The water pressure above a water droplet containing dissolved material is lowered by the Raoult effect. The size and the fraction of soluble material in an aerosol particle will determine at which supersaturation it will be activated and will become a cloud droplet. The equilibrium size of a droplet was first described by Köhler (1936), who considered the Raoult (solute) and Kelvin (curvature) effect. Quantitative knowledge of this RH effect is of substantial importance when comparing ground based observations with other optical aerosol measurements (e.g. lidar), for the purpose of aerosol correction of satellite retrievals, or in general for climate models.

The growth of an aerosol particle due to water uptake is described by the hygroscopic diameter growth factor $g(\mathrm{RH})$ which is defined as the particle diameter $D_{\text {wet }}$ at a certain RH divided by its dry diameter $D_{\text {dry }}$ :

$g(\mathrm{RH})=\frac{D_{\text {wet }}(\mathrm{RH})}{D_{\text {dry }}}$.

The RH dependence of $g(\mathrm{RH})$ can be parameterized in a good approximation by a one-parameter equation, proposed e.g. by Petters and Kreidenweis (2007):

$g\left(a_{\mathrm{w}}\right)=\left(1+\kappa \frac{a_{\mathrm{w}}}{1-a_{\mathrm{w}}}\right)^{\frac{1}{3}}$.

Here, $a_{\mathrm{w}}$ is the water activity, which can be replaced by the relative humidity RH, if the Kelvin effect is omitted. This is justified in our case, because the Kelvin effect is small for large particles $(D>100 \mathrm{~nm})$, which are relevant to light scattering and absorption. The coefficient $\kappa$ is a simple measure of the particle's hygroscopicity and captures all solute properties.

The impact of hygroscopic growth on the aerosol light scattering coefficient is usually described by the scattering enhancement factor $f(\mathrm{RH}, \lambda)$ :

$f(\mathrm{RH}, \lambda)=\frac{\sigma_{\mathrm{sp}}(\mathrm{RH}, \lambda)}{\sigma_{\mathrm{sp}}\left(\mathrm{RH}_{\mathrm{dry}}, \lambda\right)}$,

where the scattering coefficient $\sigma_{\mathrm{sp}}$ depends on the wavelength $\lambda$ and the relative humidity RH. Since no clear wavelengths dependence of $f(\mathrm{RH}, \lambda)$ was found during this study, $\lambda$ will be omitted for simplicity and the scattering enhancement factor will be written as $f(\mathrm{RH})$.

Modeled and measured enhancement factors have been described in previous studies, including maritime (Wang et al., 2007; Carrico et al., 2003), urban (Yan et al., 2009; Fitzgerald et al., 1982), continental (Sheridan et al., 2001), biomass burning (Kotchenruther and Hobbs, 1998) and free tropospheric aerosol (Fierz-Schmidhauser et al., 2010b; Nessler et al., 2005a). This study presents the first experimental data set quantifying the RH effect on aerosol light scattering of an Arctic aerosol.

\section{Experimental}

A recently developed humidified nephelometer (WetNeph), an aethalometer, a scanning mobility particle sizer (SMPS) and an optical particle counter (OPC) were operated for three months (15 July-13 October 2008) at the Zeppelin station in Ny-Ålesund, Svalbard. The Zeppelin station $\left(78^{\circ} 54^{\prime} \mathrm{N}\right.$, $11^{\circ} 53^{\prime} \mathrm{E}$ ) is situated at $475 \mathrm{~m}$ a.s.l. on the Zeppelin mountain ridge about $2.3 \mathrm{~km}$ south of the settlement $\mathrm{Ny}$-Ålesund, which is located at sea level. The station is part of the Global Atmosphere Watch (GAW) program. Low RH aerosol light scattering measurements have been performed since May 2001 at this station. Detailed information on the GAW measurement program at Ny-Ålesund and Zeppelin mountain can be obtained through the GAW station information system (GAWSIS, http://gaw.empa.ch/gawsis). Observations made at the Zeppelin station are in general less affected by local particle production occurring in the surf zone and are assumed to represent boundary layer conditions (Ström et al., 2003). Compared to the stations located at the airport and in the village, the altitude and the distance from the shoreline gives the advantage that the Zeppelin station is less susceptible to the surf and sea spray from breaking waves around the fjord area.

\subsection{Humidified and dry nephelometer}

The humidified nephelometer (WetNeph) is described in detail by Fierz-Schmidhauser et al. (2010a). Briefly, the aerosol scattering coefficient $\sigma_{\mathrm{sp}}(\lambda)$ and the back scattering coefficient $\sigma_{\mathrm{bsp}}(\lambda)$ are measured at three distinct wavelengths $(\lambda=450,550$, and $700 \mathrm{~nm})$ at defined RH between $20 \%$ and $95 \%$. For this purpose a specifically designed humidification system (consisting of a humidifier and followed by a dryer) brings the initially dry aerosol to a defined RH before its scattering properties are measured by an integrating nephelometer (TSI Inc., Model 3563). The WetNeph was programmed to measure RH cycles. In the first part of the cycle, the dry particles experience elevated RH in the humidifier, after which they are passed through the turned off dryer before their scattering properties are measured in the nephelometer (hydration mode). It should be emphasized that the temperature in the nephelometer's detection cell is $\sim 1^{\circ} \mathrm{C}$ higher than in the humidifier, thereby causing a slight RH decrease of approximately 2-6\% (see Fig. A1 in Fierz-Schmidhauser et al., 2010a) and with that a concurrent shift of the observed deliquescence RH. Deliquescence is known as a sudden uptake of water of an initially dry and solid particle at the defined deliquescence relative humidity (DRH). The deliquescence occurs at the RH where the Gibbs free energy of the wet particle becomes lower than the one of the dry particle. The behavior of dehydrating particles following the upper hysteresis branch of the growth curve is measured by setting the humidifier to its maximum $\mathrm{RH}(\sim 95 \%)$, followed by $\mathrm{RH}$ reduction 
in the dryer and measurement in the nephelometer (dehydration mode). The lowest possible RH in this mode was $\sim 65 \%$, limited by the capacity of the dryer at the high sample flow of $16.61 \mathrm{~min}^{-1}$ chosen for this campaign. Particle losses in the humidifier and dryer were characterized in a laboratory study for particle diameters $100-300 \mathrm{~nm}$ and found to be less than 5\% (Fierz-Schmidhauser et al., 2010a).

A second nephelometer (DryNeph, TSI Inc., Model 3563, operated by the Stockholm University - SU) measured the scattering coefficient as a reference in parallel always under dry conditions. The RH inside the DryNeph was always below $20 \%$.

Both nephelometers measured within the scattering angles of $7^{\circ}$ to $170^{\circ}$. The scattering coefficients for the complete angle between $0^{\circ}$ and $180^{\circ}$ were retrieved by correcting the measured values using the scheme proposed by Anderson and Ogren (1998) (truncation error correction).

\subsection{Measurement of the aerosol size distribution}

The aerosol size distribution was measured with a scanning mobility particle sizer (SMPS), which consists of a bipolar particle charger $\left({ }^{85} \mathrm{Kr}\right.$ source), a differential mobility analyzer (DMA) and a condensation particle counter (CPC, TSI Inc., Model 3772). Number size distributions in the diameter range between 14 and $820 \mathrm{~nm}$ were recorded with a time resolution of $6 \mathrm{~min}$. A correction accounting for multiply charged particles was applied. However, the data at diameters $>462 \mathrm{~nm}$ was ignored, because higher moments of the size distribution (such as surface area distribution) are significantly influenced by multiply charged particles with diameters $>820 \mathrm{~nm}$.

An optical particle counter (OPC, Model Grimm Dustmonitor 1.108) was used to measure the number size distribution of particles with an optical diameter between 0.3 and $25 \mu \mathrm{m}$ (also at dry conditions). OPC data was recorded with a time resolution of $1 \mathrm{~min}$.

The complete size distribution for diameters between $14 \mathrm{~nm}$ and $25 \mu \mathrm{m}$ was obtained by combining the SMPS data at diameters below $462 \mathrm{~nm}$ with the OPC data at diameters above $462 \mathrm{~nm}$. No remarkable difference between the two instruments was observed at the merging point, even though the SMPS measures a mobility diameter and the OPC an optical diameter.

The volume fraction of large particles $V_{\mathrm{OPC}} / V_{\text {tot }}$ is defined as the volume concentration measured by the OPC ( $D_{\text {dry }}>462 \mathrm{~nm}$, after the last SMPS bin) to total volume concentration measured by SMPS and OPC.

\subsection{Measurement of the aerosol light absorption}

To determine the absorption properties, an aethalometer (Magee Scientific, Model AE-31) was used. It measures the light attenuation by the aerosol particles (deposited on a filter) at 7 wavelengths $(\lambda=370,470,520,590,660,880$, and
$950 \mathrm{~nm}$ ). The 660-nm channel did not work properly and had to be excluded from the analysis. The light absorption coefficient $\sigma_{\text {ap }}(\lambda)$ is then derived from the light attenuation (ATN):

$\sigma_{\mathrm{ap}}(\lambda)=\frac{A}{Q} \frac{\Delta \mathrm{ATN}(\lambda)}{\Delta t} \frac{1}{C \cdot R(\operatorname{ATN}(\lambda))}$,

where $A$ is the filter spot area, $Q$ the volumetric flow, and $\triangle \operatorname{ATN}(\lambda)$ the change of light attenuation during the time interval $\Delta t$ (Weingartner et al., 2003). The empirical constant $C$ corrects for multiple scattering in the unloaded filter. Here, a value of $C=2.81$ was used, as determined for a remote background aerosol from aethalometer and multi-angle absorption photometer (MAAP) measurements at the high alpine research station Jungfraujoch (JFJ) (Collaud Coen et al., 2010). The wavelength and ATN dependent factor $R$ corrects for effects caused by the amount of particles deposited on the filter, which decrease the optical path in the filter (also called the shadowing effect). $R$ was set to be unity, since the contribution of absorption to total light extinction is small (Weingartner et al., 2003), similar to the measurements at the JFJ (Fierz-Schmidhauser et al., 2010b).

The $880-\mathrm{nm}$ channel is used to estimate aerosol equivalent black carbon (BC) concentrations, with the manufacturer's calibration. Aethalometer raw data were recorded with a time resolution of $2 \mathrm{~min}$. The data was later averaged to $1 \mathrm{~h}$ values. A comparison of the aethalometer $\sigma_{a p}(\lambda=565 \mathrm{~nm}$ ) (calculated using Eq. 4) with $\sigma_{a p}(\lambda=565 \mathrm{~nm})$ measured by a soot absorption photometer (PSAP) running in parallel showed a good agreement with $\sim 10 \%$ difference and a high correlation $\left(R^{2}=0.86\right)$. Note, that Eq. 11 was used to interpolate the aethalometer values to the PSAP wavelength of $\lambda=565$ nm.

\subsection{Aerosol filter sampling and analysis}

Aerosol filter samples for the analysis of water soluble calcium $\left(\mathrm{Ca}^{2+}\right)$, chloride $\left(\mathrm{Cl}^{-}\right)$, magnesium $\left(\mathrm{Mg}^{2+}\right)$, potassium $\left(\mathrm{K}^{+}\right)$, sodium $\left(\mathrm{Na}^{+}\right)$, sulphate $\left(\mathrm{SO}_{4}^{2-}\right)$, nitrate $\left(\mathrm{NO}_{3}^{-}\right)$and ammonium $\left(\mathrm{NH}_{4}^{+}\right)$were collected using a three-stage filter pack with a Teflon ( $2 \mu \mathrm{m}$ Zefluor) particle front filter followed by a potassium hydroxide impregnated cellulose filter (Whatman 40) and finally an oxalic acid impregnated cellulose filter (Whatman 40) (EMEP, 1995). In general, the filter pack cannot be used to separate between gas and particle phase in the case of semi-volatile compounds. Thus, for constituents that are subject to volatilization and adsorption processes on the filter, e.g. $\mathrm{NO}_{3}^{-} / \mathrm{HNO}_{3}, \mathrm{NH}_{4}^{+} / \mathrm{NH}_{3}$, $\mathrm{Cl}^{-} / \mathrm{HCl}$, only the sum can be determined accurately. $\mathrm{Ca}^{2+}$, $\mathrm{K}^{+}, \mathrm{Mg}^{2+}, \mathrm{Na}^{+}, \mathrm{SO}_{4}^{2-}$, however, can be determined from the Teflon filter alone. The filter pack was operated at flow rate of $161 \mathrm{~min}^{-1}$ and the sampling time was $24 \mathrm{~h}$ (starting time 06:00 UTC).

Prior to ion chromatography analysis, the Zefluor Teflon filters were soaked in Milli-Q water $(10 \mathrm{ml})$ and subjected 
to ultrasonic agitation (30 $\mathrm{min})$. The extracts were analyzed with respect to $\mathrm{Ca}^{2+}, \mathrm{K}^{+}, \mathrm{Mg}^{2+}, \mathrm{Na}^{+}$, and $\mathrm{NH}_{4}^{+}$on a Dionex 120DX ion chromatograph, using a Dionex cation exchange CS12A column $(4 \mathrm{~mm} \times 250 \mathrm{~mm})$, and a conductivity detector. The sample was eluted using sulphuric acid at a flow rate of $1 \mathrm{ml} \mathrm{min}-1 . \mathrm{Cl}^{-}, \mathrm{NO}_{3}^{-}$, and $\mathrm{SO}_{4}^{2-}$ were analyzed on a Dionex 120DX ion chromatograph, using a Dionex anion exchange AS9-SC column $(4 \mathrm{~mm} \times 250 \mathrm{~mm})$, and a conductivity detector. The sample was eluted using carbonate at a flow rate of $2 \mathrm{ml} \mathrm{min}^{-1}$.

\subsection{Comparison of dry nephelometer measurements}

A comparison of both nephelometers at low RH $(<40 \%)$ showed that the DryNeph measured about $28 \%$ less than the WetNeph $\left(y=1.28 x+1.64 \times 10^{-7} \mathrm{~m}^{-1}, R^{2}=0.98\right.$ for $\lambda=550 \mathrm{~nm}$, similar for the other wavelengths). A second comparison between the integrated size distribution measured by SMPS and OPC (same inlet as WetNeph) and a differential mobility particle sizer (DMPS) (same inlet as DryNeph) in the size range of 15 to $750 \mathrm{~nm}$ showed that the DMPS also measured $27 \%$ less in total number concentration than the SMPS + OPC $\left(y=1.27 x+2.21 \mathrm{~cm}^{-3}\right.$, $R^{2}=0.99$ ). The reason for this could be losses in the SU inlet system, due to longer pathways and a lower volumetric flow of $51 \mathrm{~min}^{-1}$. Most of these losses were seen in the accumulation and partly in the coarse mode. These differences were almost constant in time throughout the entire measurement period. Since both DMPS and DryNeph had separate inlet lines but a joint precipitation shelter within the SU inlet system the differences might also be explained by different flow exposition to the SU inlet and/or differences in the inlet characteristics themselves (ill-defined virtual impaction behavior and sedimentation losses for larger particles/hydrometeors). The measured size distribution (SMPS and OPC) and the measured scattering coefficients (WetNeph, when measuring at low $\mathrm{RH}$ ) were found to agree well within a performed closure study using Mie theory (see Sect. 5.5). The high correlation between the two nephelometers and the two size distribution measurements and the temporal stability of the differences suggest that all dry scattering coefficients had to be corrected for the entire period in order to make them comparable to the WetNeph data (e.g. at $\lambda=550 \mathrm{~nm}$ with $y=1.28 x+1.64 \times 10^{-7} \mathrm{~m}^{-1}$ as described above).

\subsection{Inlet systems}

The WetNeph, aethalometer, OPC, and SMPS were all connected to one inlet which had no specific aerosol diameter size cut. The inlet consisted of a vertical pipe which sampled in about $2 \mathrm{~m}$ height on the roof of the station (pipe diameter approx. $5 \mathrm{~cm}$, covered on top by a precipitation shelter). The instruments were located in the room directly below the inlet about $1-1.5 \mathrm{~m}$ away from the inlet entering the laboratory. The total flow was approx. $251 \mathrm{~min}^{-1}$ (Wet-
Neph: $16.61 \mathrm{~min}^{-1}$, SMPS: $0.31 \mathrm{~min}^{-1}$, OPC: $1.21 \mathrm{~min}^{-1}$, aethalometer: $81 \mathrm{~min}^{-1}$ ).

The inlets to the routine aerosol instrumentations run by the Stockholm University (DryNeph, CPC, DMPS, and PSAP) do not have an aerosol size characteristic cut off. The inlets consist of a $10 \mathrm{~cm}$ diameter carrier shaft with $0.25 \mathrm{inch}$ stainless steel tubing to support the different instruments. The dry nephelometer has its own 0.25 inch inlet with a flow of approx. $61 \mathrm{~min}^{-1}$. The PSAP, CPC, and DMPS share another 0.25 inch inlet with a total flow of approx. $5.51 \mathrm{~min}^{-1}$. The shaft and tubing are covered by a precipitation shelter approx. $25 \mathrm{~cm}$ high and are approx. $25 \mathrm{~cm}$ in diameter. The low flow rates of around $5-101 \mathrm{~min}^{-1}$ will, for the most time, prevent hydrometeors and large aerosol particles to enter the sampling system.

During transport to the instruments, the ambient air sample will equilibrate to room temperature, which is typically much higher than the outside temperature. This often makes the air dryer than $10 \% \mathrm{RH}$.

\section{Model description}

A computer model based on Mie theory has been developed for the calculation of $f(\mathrm{RH})$. It calculates optical properties for polydisperse, internally mixed aerosol particles, which are assumed to be spherical and to have a homogeneous chemical composition. The Mie routine is based on the code of Bohren and Huffmann (2004). The aerosol size distribution and the complex refractive index are needed as input parameters. Both input variables change with changing RH due to hygroscopic growth.

The change of the dry number size distribution can be calculated as follows: First, the wet particle diameter $D_{\text {wet }}$ has to be determined by multiplying $D_{\text {dry }}$ with $g(\mathrm{RH})$ :

$D_{\text {wet }}=g(\mathrm{RH}) D_{\text {dry }}$.

Normally, $g(\mathrm{RH})$ will be a function of $D_{\text {dry }}$. Here, $g(\mathrm{RH})$ is assumed to be independent of the diameter, therefore the wet number size distribution $\mathrm{d} N / \mathrm{d} \log D_{\text {wet }}$ will shift to larger diameters.

The complex refractive index of grown particles at high $\mathrm{RH}$ is obtained by a volume weighting of the dry refractive index $m_{\text {dry }}$ with the refractive index of water $m_{\mathrm{H}_{2} \mathrm{O}}(\lambda=550 \mathrm{~nm})=1.333$ (Hale and Querry, 1973):

$m_{\mathrm{wet}}=\frac{m_{\mathrm{dry}}+m_{\mathrm{H}_{2} \mathrm{O}}\left(g^{3}-1\right)}{g^{3}}$.

In this work, a fixed dry refractive index of $\left(\mathrm{NH}_{4}\right)_{2} \mathrm{SO}_{4}$ (ammonium sulphate) $m_{\text {dry }}(\lambda=550 \mathrm{~nm})=1.53$ (interpolated from Toon et al., 1976) was used. Neglecting the imaginary part of the refractive index is only possible if no strong absorbing aerosol is found, which is the case for our study. It will be shown in Sect. 5 that this is a reasonable assumption. 


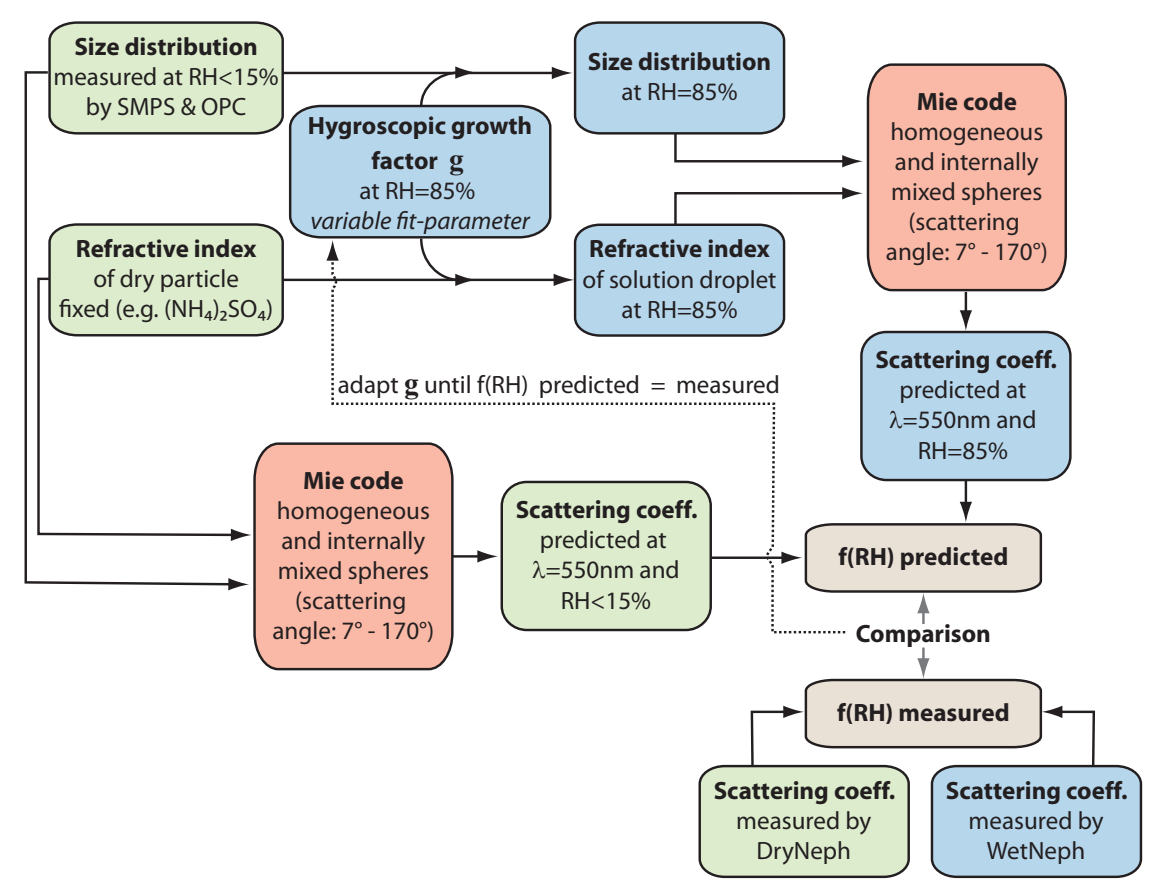

Fig. 1. Scheme of the growth factor retrieval (backward calculation). See text for details.

\subsection{Forward calculation}

If the growth factor, the refractive index and the size distribution are known, the scattering properties can be calculated for the dry and the high RH case (using Eqs. 1-6 and Mie theory). $f(\mathrm{RH})$ is then determined by Eq. (3). These calculations were done for the entire scattering angle $\left(0-180^{\circ}\right)$. The resulting $f(\mathrm{RH})$ were then compared to the measurements, which were corrected for the nephelometer truncation error (see Sect. 2.1). The hygroscopic growth was retrieved via Mie theory (see Sect. 3.2) and for comparison assumed to be constant throughout the entire period (see Sect. 5.5).

\subsection{Backward calculation - retrieval of the apparent hygroscopic growth factor}

Independent measurements of the hygroscopic diameter growth factors (e.g. through measurements of $g(\mathrm{RH})$ by a hygroscopic tandem differential mobility analyzer) were not available for this study, which makes it impossible to directly calculate or predict the scattering enhancement $f(\mathrm{RH})$ (as done e.g. by Fierz-Schmidhauser et al., 2010b, for JFJ). However, measured wet and dry scattering coefficient data and the Mie model can be used to infer the hygroscopic growth of the detected aerosol, following the retrieval scheme depicted in Fig. 1. For this purpose $g(\mathrm{RH})$ was varied until the calculated $f(\mathrm{RH})$ for the measured size distribution matched the measured value within $2 \%$. The dry refractive index was again assumed to be equal to the value of
$\left(\mathrm{NH}_{4}\right)_{2} \mathrm{SO}_{4}$. The retrieval was performed at $\mathrm{RH}=85 \%$ and for $\lambda=550 \mathrm{~nm}$. $g(\mathrm{RH})$ can be transformed to $\kappa$ using Eq. (2) to calculate $g(\mathrm{RH})$ at additional values of $\mathrm{RH}$.

These calculations were performed in the specific scattering angles of the nephelometer $\left(7-170^{\circ}\right)$, to avoid the truncation error correction. By doing so, the calculated values can be directly compared to the direct measurements. The angular nephelometer illumination sensitivity (Anderson et al., 1996) was also accounted for in the Mie code.

Although this retrieval is based on strong simplifications (spherical particles, internal homogeneous mixture, and a fixed dry refractive index for the entire period), it will give useful insights to the apparent physical growth of the measured aerosol.

\section{Simulation of a passive sea salt tracer}

A sea salt tracer was simulated for the Zeppelin station by combination of the Lagrangian particle dispersion model (LPDM) FLEXPART (Stohl et al., 2005) and sea salt aerosol sources parameterized from model wind speeds. In a simplified approach the released sea salt aerosol was treated as a tracer with an e-folding lifetime of $24 \mathrm{~h}$. This analysis gives additional insights concerning the aerosol origin and its composition and is used to support our hypotheses formulated in Sect. 5. 


\subsection{Dispersion model}

FLEXPART was set up in backwards mode and operated on 3-h global meteorological fields as retrieved from ECMWF analysis and forecasts with a horizontal resolution of $1^{\circ}$ by $1^{\circ}$ on 91 vertical levels. The output of residence times was stored with a horizontal resolution of $0.5^{\circ}$ by $0.5^{\circ}$ covering the area north of $45^{\circ} \mathrm{N}$ and for vertical level tops at 100 , 500,1000 , and $3000 \mathrm{~m}$ above model ground. The model was initialized every $3 \mathrm{~h}$ for the period 15 June to 15 October 2008 and integrated backwards in time for $120 \mathrm{~h} .50000$ particles were released in each run at the Zeppelin station at $475 \mathrm{~m}$ a.s.l.

\subsection{Emission calculation}

Sea salt sources from open water were calculated following the parametrization given by Gong (2005) based on simulated $10-\mathrm{m}$ wind speeds. Wind speeds were taken from ECMWF analysis and $+3 \mathrm{~h}$ forecast fields and were available every $3 \mathrm{~h}$ with a $1^{\circ}$ by $1^{\circ}$ horizontal resolution. Sea salt in 3 different size ranges was considered: $0.01-10 \mu \mathrm{m}$, $0.1-10 \mu \mathrm{m}$, and 1-10 $\mu \mathrm{m}$. Emissions from ice covered areas were considered separately according to the parametrization by Yang et al. (2008) and references therein. The fraction of open sea water was obtained from daily sea ice analysis (http://cersat.ifremer.fr/data/discovery/by_parameter/sea_ ice/psi_ssmi).

The sea salt aerosol number concentrations at the receptor site were calculated by summation of the products of residence times and sea salt over all grid boxes and for each simulated time, $t$ :

$S_{N}(t)=\sum_{l} \sum_{i, j} \exp \left(\frac{-T_{l}}{\tau_{\mathrm{ss}}}\right) \tau_{i, j, l} \frac{F_{N_{i, j}}}{V_{i, j}}$,

where $T_{l}$ is the time before arrival, $\tau_{\mathrm{ss}}$ the life-time of the sea salt tracer, $\tau$ the residence times in units of $\mathrm{s}, F_{N}$ the sea salt source (from open water plus ice sheets) in units of $\mathrm{N} /\left(\mathrm{m}^{2} \mathrm{~s}\right)$ and $V$ the grid box volume of the lowest FLEXPART output grid ( $100 \mathrm{~m}$ level top). The summation runs over all horizontal grid boxes $i, j$ and along the integration time $l$.

\section{Results}

Figure 2 shows one day of the recorded data (20 August 2008). The hourly recorded webcam pictures from the Zeppelin station (with view towards the settlement of Ny-Ålesund and the Kongsfjorden) are helpful additional information about the current weather conditions (see Fig. 2a, webcam pictures are provided by NILU on their webserver ftp://ftpguest:guest@ftp.npolar.no/In/kim/zepold/ ZeppelinCam.jpg, last checked on 9 December 2009). The beginning of the measurement period was characterized by $24 \mathrm{~h}$ of sunlight per day (until mid September when the daynight cycle returned). The RH inside the WetNeph was periodically increased and decreased (see Fig. 2b) and the corresponding scattering coefficients measured (blue line in Fig. 2c). The DryNeph measured constantly at dry conditions (red line in Fig. 2c) in parallel to the WetNeph. The dry number size distribution was measured by the SMPS and OPC at the same inlet as the WetNeph (see Fig. 2d). On 20 August the number size distribution was characterized by two distinct modes at $40 \mathrm{~nm}$ and $110 \mathrm{~nm}$. The aerosol absorption coefficients determined by the aethalometer (using Eq. 4) are seen in Fig. 2e, showing that the absorption coefficients were about two orders of magnitude lower than the scattering coefficients.

An overview of the entire measurement period can be found in Fig. 3. The aerosol particle number concentration (blue curve in Fig. 3e) shows a temporal decrease towards October, while the total surface area concentration shows no clear increase or decrease (orange curve in Fig. 3e). A maximum in the aerosol number concentration in the summer has been previously observed by Ström et al. (2003) at the Zeppelin station and also at other Arctic sites, e.g. at Barrow, Alaska by Bodhaine (1989) and Quinn et al. (2002) who mention that the maximum particle concentration in summer in the Arctic could relate to the formation of biogenic sulfur particles. The temporal evolution of the scattering coefficient shows no clear trend, but certain events with elevated values are observed (Fig. 3a). These events are probably caused by sea salt particles (larger particles with higher scattering efficiency and larger surface area), which is also reflected in a more dominant coarse mode in the surface size distribution during these periods (Fig. 3d). Bodhaine (1989) and Quinn et al. (2002) also found for Barrow, Alaska, a minimum in the scattering coefficient in summer and an increase towards fall and winter, attributing this increase to an enhanced sea salt influence. The single scattering albedo $\omega_{0}$ is also very high during these sea salt events $\left(\omega_{0}>0.98\right)$, meaning that the particles are almost pure scatterers (see Sect. 5.4). Quinn et al. (2002) found similarly high values of $\omega_{0}$ during summer for Barrow, Alaska.

The $\mathrm{BC}$ concentrations measured by the aethalometer were on average $7.2 \mathrm{ng} \mathrm{m}^{-3}$ (90th percentile: $31 \mathrm{ng} \mathrm{m}^{-3}$ ), which is similar to the findings of Eleftheriadis et al. (2009) who determined a mean value of $\sim 7 \mathrm{ng} \mathrm{m}^{-3}$ for June to September from 1998 to 2007 . The aerosol filter analyses were only available for part of the three month period (see Fig. 4). Major sea salt constituents such as $\mathrm{Na}^{+}$and $\mathrm{Cl}^{-}$ were always present though they were more dominant during the last third of the campaign and during short periods in between, when the relative mass fraction of non-sea salt $\mathrm{NO}_{3}^{-}$ and $\mathrm{NH}_{4}^{+}$concurrently decreased. The observations at Zeppelin indicated no clear long range transport of pollution to the measurement site, as can also be confirmed by transport simulations. The FLEXPART backward simulations showed that the air masses reaching the Zeppelin station mainly originated from the Arctic region surrounding Svalbard and the 

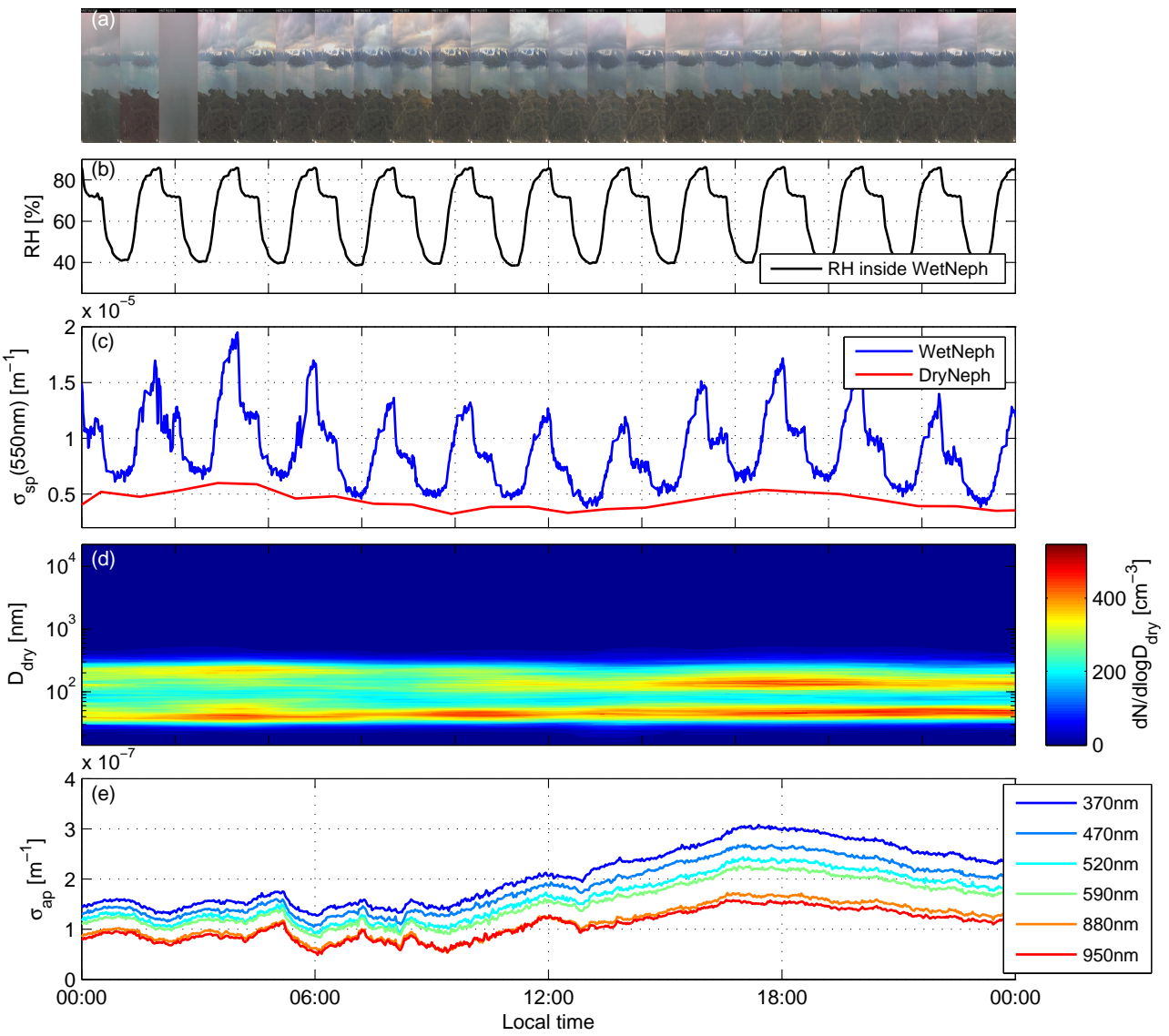

Fig. 2. Example of the recorded data for 20 August 2008 (local time). (a): Hourly webcam pictures from Zeppelin station. (b): Relative humidity inside the WetNeph. (c): Measured scattering coefficients $\sigma_{\mathrm{sp}}(\lambda=550 \mathrm{~nm})$ in the DryNeph (red line, hourly averages) and in the WetNeph (blue line, 2 min values). (d): Number size distribution measured by SMPS and OPC. (e): Absorption coefficient $\sigma_{\text {ap }}$ determined by the aethalometer at different wavelengths (one hour moving mean applied). The 660-nm channel was not working properly and had to be excluded.

North Atlantic Ocean (see Fig. 5). Hence, the measurement period was characterized by maritime and rather clean air masses.

The scattering enhancement factor $f(\mathrm{RH})$ was calculated using Eq. (3). Since no pronounced wavelength dependency of $f(\mathrm{RH})$ was found, we will focus on the $550 \mathrm{~nm}$ wavelength only.

Humidograms of $f(\mathrm{RH})$, defined as a plot of $f(\mathrm{RH})$ vs. RH, were determined as daily median values of $f(\mathrm{RH})$ (with a 2\% RH bin size and synchronized to the aerosol filter sampling intervals). As mentioned above, measurements at $\mathrm{RH}<65 \%$ are always part of the hydration branch. It was therefore technically not possible to detect any efflorescence at $\mathrm{RH}<65 \%$. Measurements above $\sim 65 \% \mathrm{RH}$ were done in both the hydration and dehydration mode (see Sect. 2.1). Unfortunately, no clear efflorescence was observed at $\mathrm{RH}>65 \%$.

An example humidogram characterized by a smoothly increasing $f(\mathrm{RH})$ and without a distinct deliquescence transition is seen in Fig. 6a (daily average), indicating that the par- ticles were always liquid. A second example humidogram with a distinct increase of $f(\mathrm{RH})$ at $\mathrm{RH} \sim 70 \%$ is shown in Fig. 6b. This increase, known as deliquescence, can be explained by a sudden water uptake of the solid aerosol particle becoming (at least partly) liquid. It has to be repeated that the actual DRH of the aerosol is a few percent higher than what the WetNeph measures due to temperature differences between humidifier and nephelometer (see Sect. 2.1).

The temporal evolution of the ambient $f(\mathrm{RH})$ at $\mathrm{RH}=85 \%$ is shown in Fig. 7d (black points, daily median values between $84 \%<\mathrm{RH}<86 \%$ ). The values measured at $\mathrm{RH}=85 \%$ are in the range of $f(\mathrm{RH}) \sim 2-6$, which means two- to sixfold increase of the ambient scattering coefficient compared to dry conditions. Campaign average and percentile values of $f(\mathrm{RH}=85 \%)$ are given in Table 1 . This can be compared e.g. to values for biomass burning aerosols, where Kotchenruther and Hobbs (1998) measured lower values of $f(\mathrm{RH}=80 \%, \lambda=550 \mathrm{~nm})=1.01-1.5$ or to free tropospheric aerosol measured at Jungfraujoch (including Saharan dust events) with values of $f(\mathrm{RH}=85 \%, \lambda=550 \mathrm{~nm})=1.2-3.3$ 


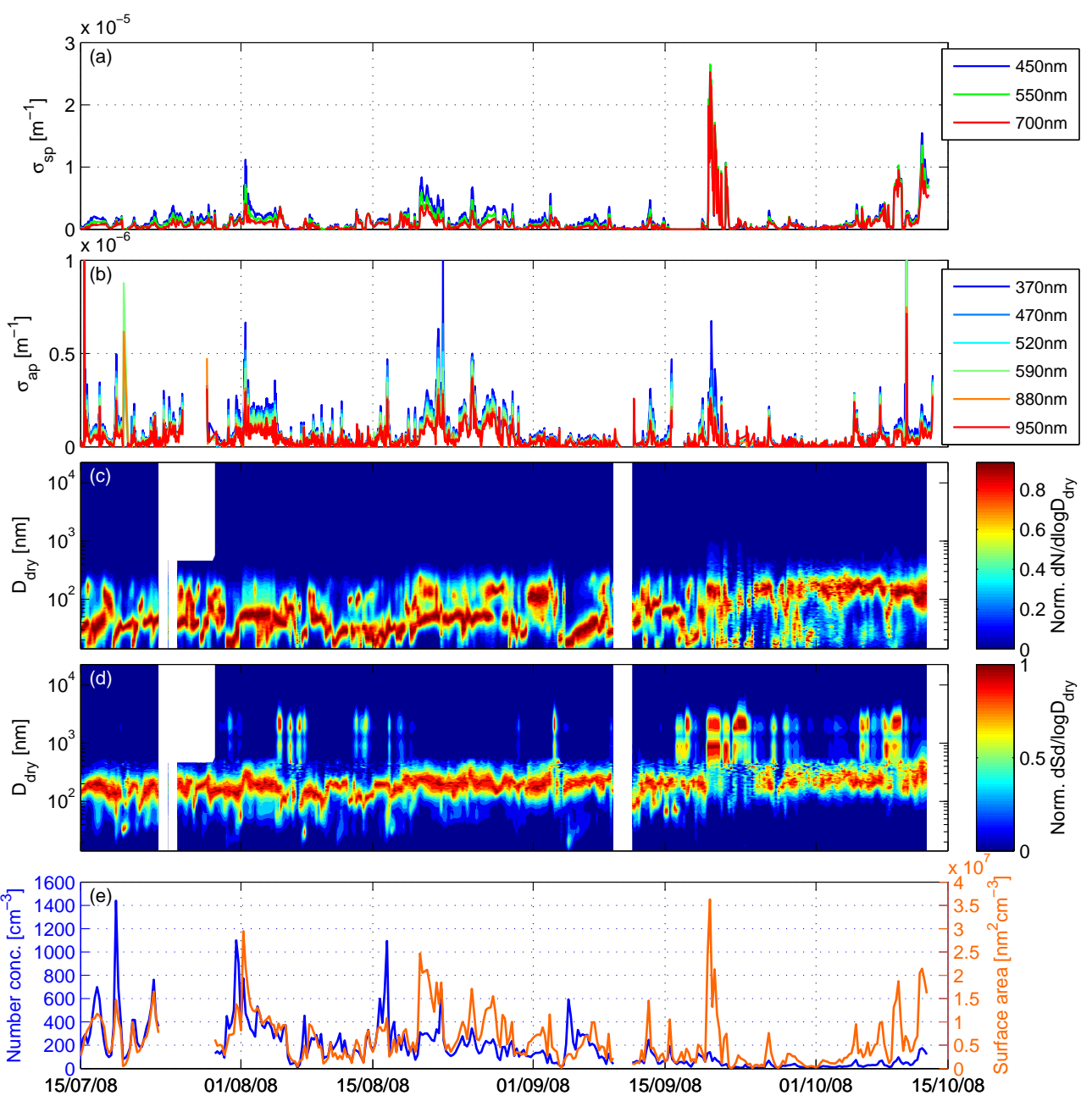

Fig. 3. Overview of recorded data of the entire campaign. (a): Dry scattering coefficients at 450 , 550 , and $700 \mathrm{~nm}$ (DryNeph, hourly averages). (b): Absorption coefficients at different wavelengths (aethalometer, hourly averages, without $660 \mathrm{~nm}$ ). (c): Normalized number size distribution (SMPS and OPC, $6 \mathrm{~h}$ averages). (d): Normalized surface size distribution measured (SMPS and OPC, $6 \mathrm{~h}$ averages). (e): Total number concentration (blue line) and total surface area (orange line) measured by SMPS and OPC (6-h averages).

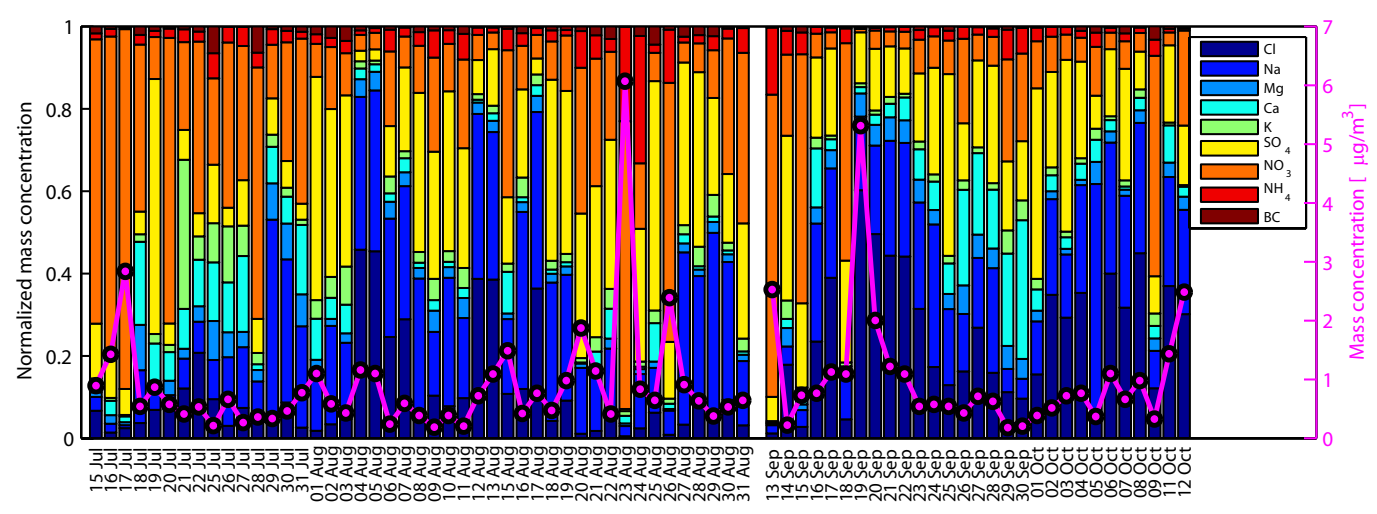

Fig. 4. Normalized filter measurements of aerosol components (colored bars) and the total mass (magenta line). Shown are only days, where all aerosol components were analyzed completely (exception: 26 and 27 July, where no BC measurements were available, but are assumed to be as low as on the other days). The measurements were performed without a specific size cut (open face sampler). 
Table 1. Campaign mean, standard deviation (STD), and percentile values of the scattering enhancement factor $f(\mathrm{RH}=85 \%)$, its fit parameter $\gamma_{>75 \%}$ (both at $\lambda=550 \mathrm{~nm}$ ), the apparent hygroscopic growth factor $g(\mathrm{RH}=85 \%)$, and its $\kappa$ value (both derived via Mie theory as described in Sect. 3.2).

\begin{tabular}{llllll}
\hline & mean & STD & median & 10th perc. & 90th perc. \\
\hline$f(\mathrm{RH}=85 \%)$ & 3.24 & 0.63 & 3.12 & 2.54 & 3.93 \\
$\gamma>75 \%$ & 0.58 & 0.09 & 0.57 & 0.47 & 0.69 \\
$g(\mathrm{RH}=85 \%)(\mathrm{Mie})$ & 1.61 & 0.12 & 1.60 & 1.47 & 1.77 \\
$\kappa(\mathrm{Mie})$ & 0.57 & 0.17 & 0.55 & 0.39 & 0.80 \\
\hline
\end{tabular}

(Fierz-Schmidhauser et al., 2010b). Similarly high values were measured for maritime air by Carrico et al. (2003) with $f(\mathrm{RH}=82 \%, \lambda=550 \mathrm{~nm})=2.45$, although at slightly lower $\mathrm{RH}$. Our mean values can be transformed to the RH values used in the previous mentioned studies (using Eq. 3): $f(R H=82 \%)=2.89$ and $f(R H=80 \%)=2.71$.

\subsection{Parametrization of $f(\mathrm{RH})$}

The humidograms of $f(\mathrm{RH})$ measured at Zeppelin station can be well described using an empirical $\gamma$-model, which has also been used in previous studies e.g. by Gassó et al. (2000) and Kotchenruther and Hobbs (1998) and goes back to the work of Kasten (1969):

$f(\mathrm{RH})=(1-\mathrm{RH})^{-\gamma}$

where $\gamma$ parameterizes the magnitude of the scattering enhancement. Although more advanced multi-parameter equations have been proposed in the literature e.g. by Carrico et al. (2003), it turns out that Eq. (8) is sufficient to parameterize the behavior of $f(\mathrm{RH})$ observed in this study. $f(\mathrm{RH})$ measured at high RH $(>75 \%)$ and low RH $(<65 \%)$ were fitted separately to get a criterion for the presence or absence of a deliquescence transition. The time series of the high $\mathrm{RH}$ fit parameter $\gamma_{>75 \%}$ is seen in Fig. 7a. The error bars denote the $95 \%$ confidence level of the fitted parameter and are in general very small, showing that the $\gamma$-model works well for the aerosol type measured at the Zeppelin station. Larger error bars are mostly the result of extremely low concentrations, where the noise of the measured scattering coefficients caused a high uncertainty in $f(\mathrm{RH})$. It can also be caused by air mass changes during the averaging period of one day. The advantage of using the fit-parameter $\gamma_{>75 \%}$ instead of $f(\mathrm{RH}=85 \%)$ is that measurements taken at different $\mathrm{RH}$ can be directly compared, and that $\gamma_{>75 \%}$ describes the humidity dependence of $f(\mathrm{RH})$ for the entire range $\mathrm{RH}>75 \%$. Campaign average and percentile values of $\gamma>75 \%$ can be found in Table 1.

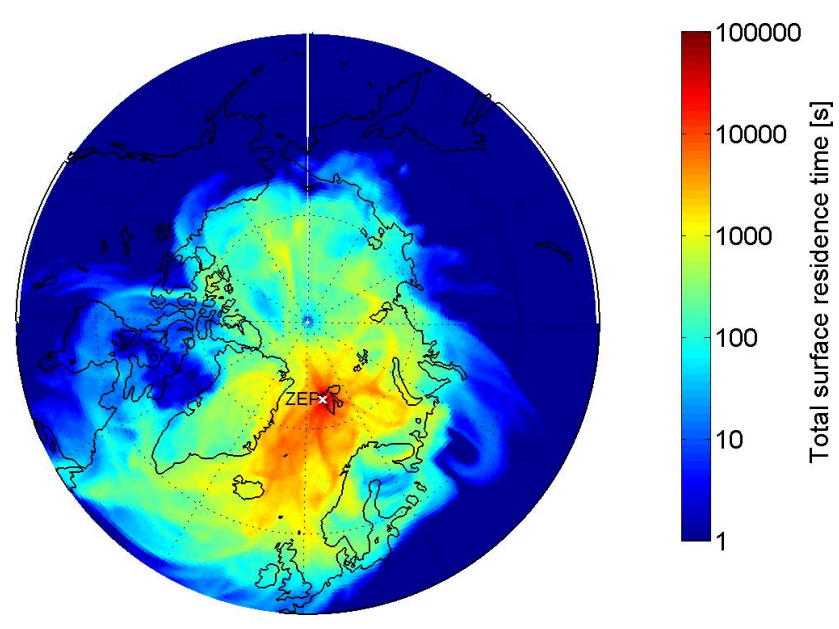

Fig. 5. Total surface residence time for the Zeppelin station (ZEP, see cross) for the period 15 July to 15 October 2008.

\subsection{Deliquescence caused by sea salt}

The fit parameters $\gamma>75 \%$ and $\gamma_{<65 \%}$ can be used to check for possible deliquescence transitions. We can define a hysteresis index $\eta$ :

$\eta=1-\frac{\gamma_{<65 \%}}{\gamma>75 \%}$,

which describes the magnitude of a deliquescence transition at $65 \%<\mathrm{RH}<75 \%$ within the range of $\eta=0$ (no deliquescence) and $\eta=1$ (very distinct deliquescence, i.e. completely undissolved at $\mathrm{RH}<75 \%$ ). The time series of $\eta$ is shown in Fig. 7b. It can be seen that deliquescence is more often observed during the last third of the campaign (15 September to 15 October 2008). The color code of the circles in Fig. 7b denotes the aerosol volume fraction $V_{\mathrm{OPC}} / V_{\text {tot }}$, which hereafter will be called volume fraction of large particles. The volume fraction of large particles is most likely dominated by sea salt particles because the observed $f(\mathrm{RH})$ would be much smaller if it was mineral dust (e.g. $f(\mathrm{RH}=82 \%)=1.69$ measured by Carrico et al., 2003). A high volume fraction of large particles (reddish color in Fig. 7b) thus indicates high sea salt influence. High values of $\eta$ occurred whenever the volume fraction of large particles was high, indicating that the appearance of a distinct deliquescence is linked to the presence of sea salt. The few values of $\eta<0$ are not physically reasonable and are caused by possible air mass changes within the averaging time of one day or noisy data at times with extremely low concentrations (especially at the beginning of September). Figure 8b shows the scatter plot of $\eta$ versus the volume fraction of large particles, where the color code denotes the $\mathrm{Na}^{+}$-mass fraction determined from the filter analysis. A positive correlation can be seen between the possibility of a deliquescent transition and the sea salt content. It should be mentioned that organic species in the aerosol chemical composition will most probably lower the 
(a)

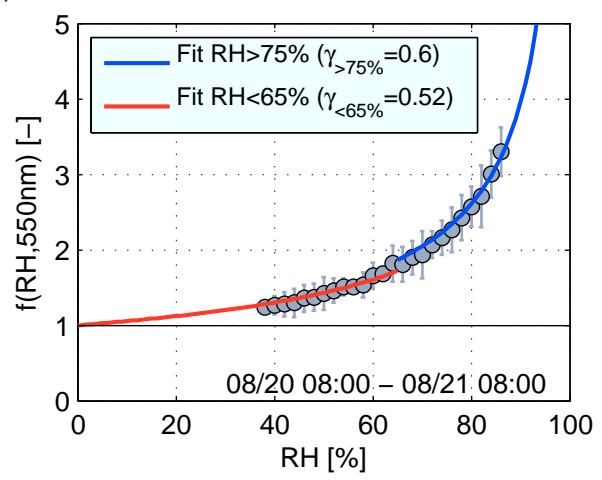

(b)

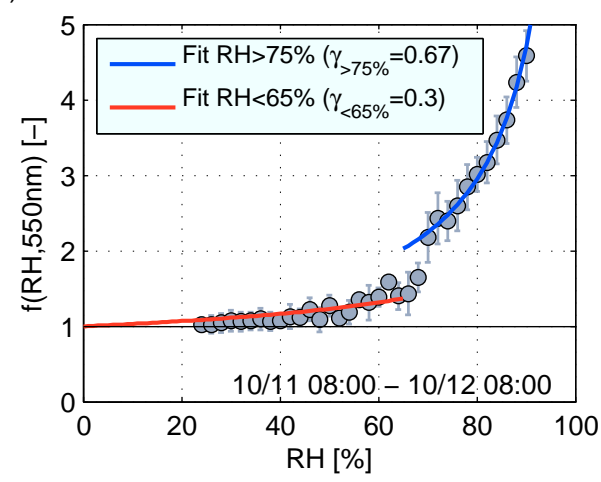

Fig. 6. Measured humidograms of $f(\mathrm{RH}, \lambda=550 \mathrm{~nm})$, given as daily median values, where the error bars denote the standard deviation. (a): Example from 20 August 2008. (b): Example from 11 October 2008. Solid lines are $\gamma$-fits for the values with RH $>75 \%$ (blue line) and for $\mathrm{RH}<65 \%$ (red line). The time periods correspond to the filter sampling time (local time).

magnitude of the deliquescence (Ming and Russel, 2001) as organics will also decrease the hygroscopic growth in general (see Sect. 5.3).

The sea salt number concentration derived from the FLEXPART analysis (see Sect. 4) also indicates that sea salt is more abundant during the last third of the campaign. The times for which elevated sea salt number concentrations are predicted (see red line in Fig. 7c), correspond partly to the times when deliquescence is clearly observed (high $\eta$ values in Fig. 7b). The simplified sea salt tracer analysis only provides qualitative information, while the modeled number concentrations did not match to the SMPS and OPC measurements quantitatively.

\subsection{Compensating effects of size and hygroscopicity}

Neither the observed $f(\mathrm{RH})$ nor the $\gamma_{>75 \%}$ showed a clear seasonal trend (see Fig. 7a, d), nor were they positively correlated with the occurrence of sea salt (see Fig. 8a), as inferred from the volume fraction of large particles $\left(V_{\mathrm{OPC}} / V_{\text {tot }}\right)$.

Two hypotheses can be put up for the explanation of these findings:

1. The aerosol properties are constant in time.

2. Compensating effects of different varying aerosol properties cause an almost constant $f(\mathrm{RH})$.

The first hypothesis can be excluded given the observed variations of the size distribution, the chemical composition and the influence of sea salt. The temporal evolution of the volume fraction of large particles $\left(V_{\mathrm{OPC}} / V_{\text {tot }}\right)$ and the $\mathrm{Na}^{+}$mass fraction is shown in Fig. 7c. The fraction is increasing towards the end of the sampling period, pointing towards a higher sea salt influence. The clear change in the aerosol number and surface area size distribution was already seen in Fig. 3. As mentioned above, the aerosol filter analysis showed a clear change in aerosol chemical composition (see
Fig. 4). The FLEXPART sea salt tracer analysis also showed a possible change in chemical composition, with a higher sea salt probability especially during the second half of September (red line in Fig. 7c). This confirms that the aerosol properties did change with time.

How would the optical properties of an aerosol with a constant chemical composition react to a change only in size? This is illustrated by assuming a certain constant hygroscopic growth and refractive index and performing Mie calculations to calculate $f(\mathrm{RH})$ exemplarily at $\mathrm{RH}=85 \%$ (as described in Sect. 3.2) using the measured size distributions as input. The result for assuming a strongly hygroscopic salt (sodium chloride, $\mathrm{NaCl}$ ), an intermediately hygroscopic salt $\left(\left(\mathrm{NH}_{4}\right)_{2} \mathrm{SO}_{4}\right)$ and for weakly hygroscopic organics is shown in Fig. 7d. For $\mathrm{NaCl}$ and $\left(\mathrm{NH}_{4}\right)_{2} \mathrm{SO}_{4}$ the growth factors were taken from Topping et al. (2005) and the refractive indices from Toon et al. (1976). For the organics, a value of $g=1.2$ (at $\mathrm{RH} \approx a_{\mathrm{w}}=85 \%$ ) was taken from Sjogren et al. (2008), which is representative of aged organic aerosol in the free troposphere and a corresponding refractive index was taken from Nessler et al. (2005a). $f(\mathrm{RH})$ of pure $\mathrm{NaCl}$ would be in general much higher (mean 7.4 at $\mathrm{RH}=85 \%$, blue points in Fig. 7d) than measured. The blue points, assuming pure $\mathrm{NaCl}$, clearly illustrate that the increase in particle size during the period after 15 September would lead to distinctly lower $f(\mathrm{RH})$ if the chemical composition was constant. Assuming pure organics results in much lower $f(\mathrm{RH})$ (mean 1.6 at $\mathrm{RH}=85 \%$, green points in Fig. 7d). The size effect is also seen though less pronounced. $f(\mathrm{RH})$ calculated for pure $\left(\mathrm{NH}_{4}\right)_{2} \mathrm{SO}_{4}$ (mean 3.1 at $\mathrm{RH}=85 \%$, red points in Fig. $7 \mathrm{~d}$ ) are in the range of our measurements. The size effect during the period with high volume fraction of large particles is also seen for pure $\left(\mathrm{NH}_{4}\right)_{2} \mathrm{SO}_{4}$, while the measured $f(\mathrm{RH})$ decreased only very little (see also Fig. 8a).

The compensating effects of changes in size and hygroscopicity (chemical composition) on $f(\mathrm{RH})$ can be 

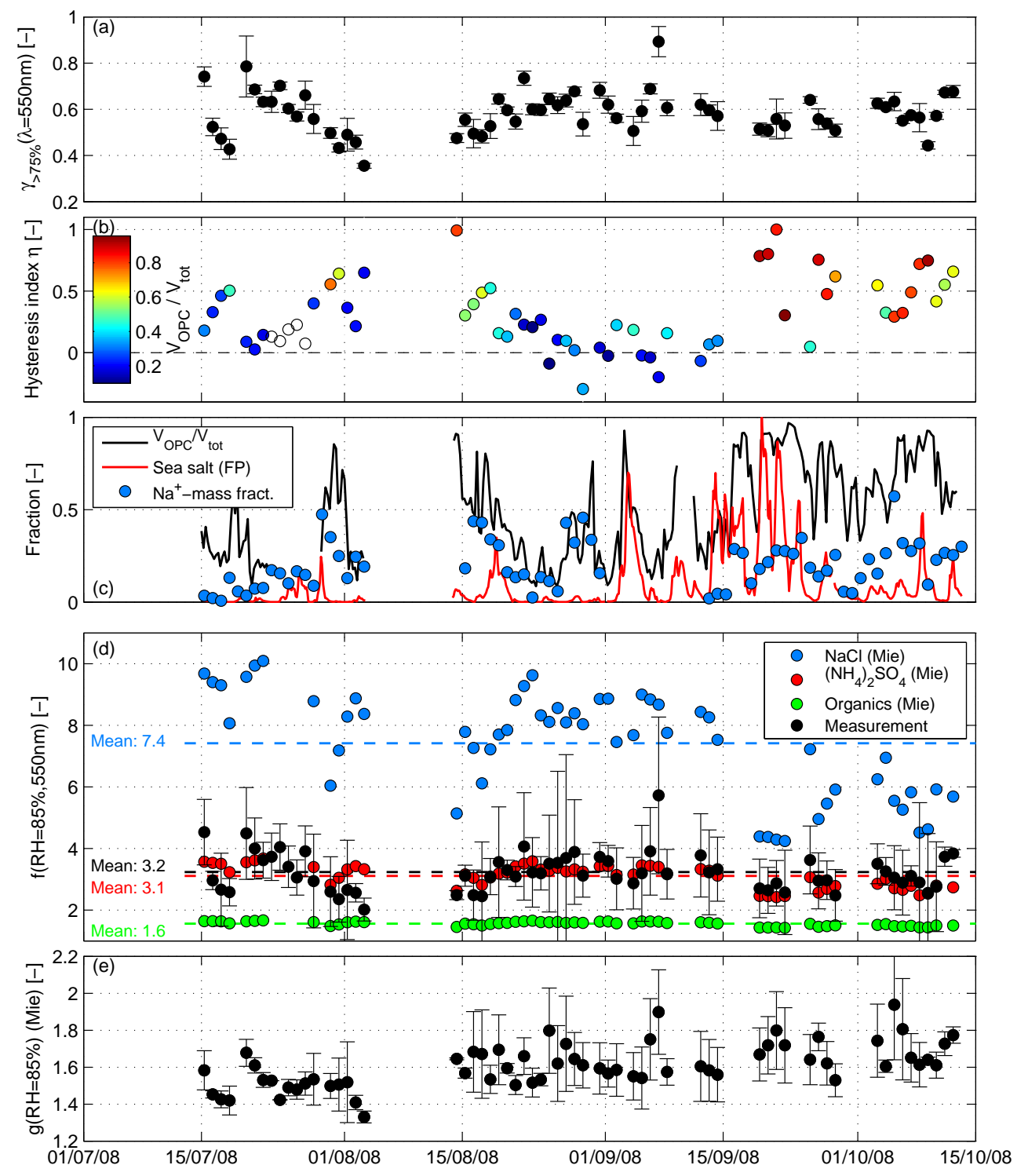

Fig. 7. (a): Time series of fit-parameter $\gamma>75 \%$, error bars indicate the $95 \%$ confidence level. (b): Hysteresis index $\eta$, color code indicates the volume fraction of large particles $\left(V_{\mathrm{OPC}} / V_{\mathrm{tot}}\right)$. (c): Measured volume fraction of large particles $V_{\mathrm{OPC}} / V_{\text {tot }}$ (black line), normalized sea salt number concentration for the $1-10 \mu \mathrm{m}$ particle diameter size range as derived from FLEXPART analysis (red line) and measured $\mathrm{Na}^{+}$-mass fraction (blue points). (d): Calculated $f(\mathrm{RH}=85 \%, \lambda=550 \mathrm{~nm})$ using the measured size distribution and assuming a constant chemistry (constant hygroscopic growth and complex refractive index) and measurement of $f(\mathrm{RH}=85 \%, \lambda=550 \mathrm{~nm})(\mathrm{black}$ circles, error bars are standard deviation of daily median values). (e): Retrieved growth factor $(g(\mathrm{RH}=85 \%))$. See retrieval scheme in Fig. 1 . Data is only shown for periods with available WetNeph measurements.

illustrated by performing Mie calculations with a model aerosol consisting of various fractions of a highly hygroscopic inorganic salt $(\mathrm{NaCl})$ and weakly hygroscopic organics. The corresponding growths factors and refractive indices (references see above) were obtained through volume weighting (also known as Zdanovskii-Stokes-Robinson approach). A single log-normal size distribution with varying mode diameter $D_{\text {mod }}$ and a fixed geometric mean deviation width of 1.8 was chosen as input. Figure 9 shows a clear decrease of $f(\mathrm{RH}=85 \%)$ with increasing size when assum- ing the chemical composition to be constant. It also decreases with increasing organic contribution. This is reasonable, since organic species reduce the hygroscopic growth of sea salt particles significantly (Ming and Russel, 2001). The measured values of $f(\mathrm{RH}=85 \%)$ versus the number mean diameter $D_{\text {mean }}$ are included in Fig. 9. They do not follow the isolines of constant chemical composition but show a rather constant $f(\mathrm{RH}=85 \%)$ with a clear change in particle diameter. Compared to the model calculations they show an increased inorganic contribution (more $\mathrm{NaCl}$ ) with increasing 


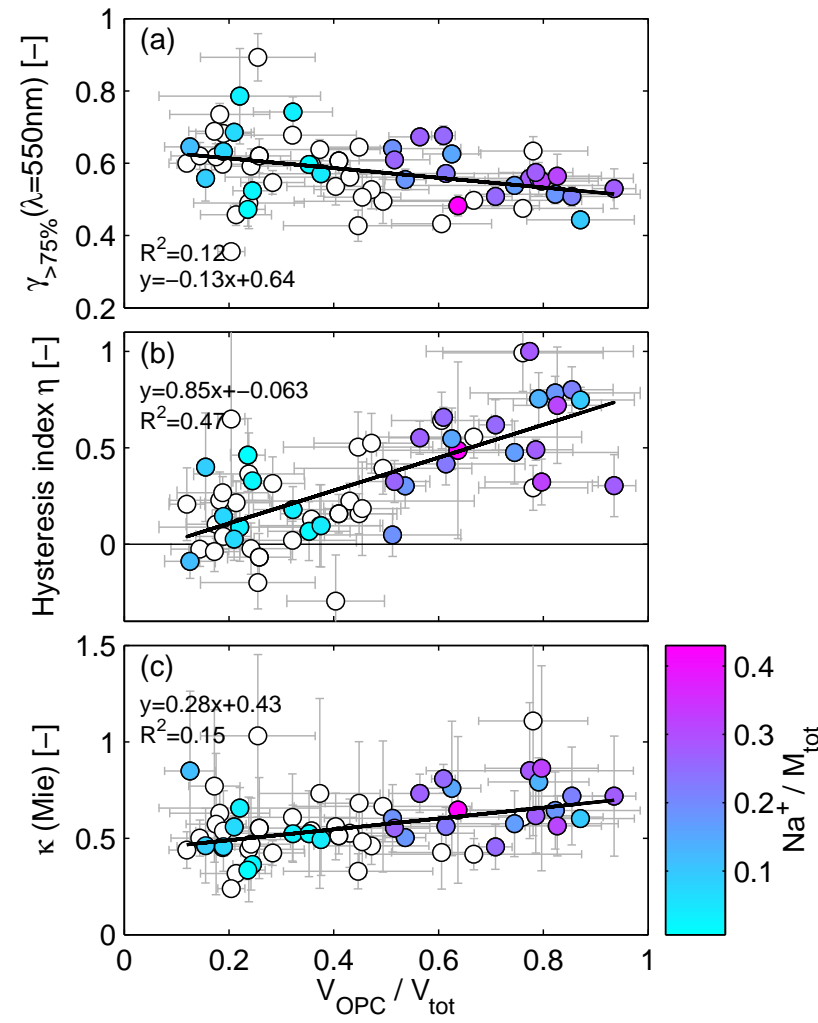

Fig. 8. (a): Fit-parameter $\gamma_{>75} \%$ of $f(\mathrm{RH})$ versus the volume fraction of large particles $\left(V_{\mathrm{OPC}} / V_{\mathrm{tot}}\right)$. (b): Hysteresis index $\eta$ versus $V_{\mathrm{OPC}} / V_{\text {tot }}$. (c): Retrieved $\kappa$ (retrieved at $\mathrm{RH}=85 \%$ ) versus $V_{\text {OPC }} / V_{\text {tot }}$. Color code in all panels indicates the $\mathrm{Na}^{+}$-mass fraction determined from filter measurements (only for days where the mole fraction $0.3<\mathrm{Na}^{+} / \mathrm{Cl}^{-}<3$ ). Black lines represent a weighted least-square regression.

size, which results in a higher hygroscopic growth. Note that $D_{\text {mean }}$ (obtained from the measured size distribution by $\left.D_{\text {mean }}=N^{-1} \int_{0}^{\infty}\left(D_{\text {dry }} \mathrm{d} N / \mathrm{d} \log D_{\text {dry }}\right) \mathrm{d} \log D_{\text {dry }}\right)$ is not directly comparable to $D_{\text {mod }}$ of the log-normal size distribution, but gives the right range for the measured values.

The fact that the measured $f(\mathrm{RH}=85 \%)$ showed no significant change during sea salt periods, with a concurrent increase of mean particle size, implies that also particle hygroscopicity increased during these periods. Lacking a direct measurement of particle hygroscopicity, the magnitude of hygroscopic growth factors and their trends were estimated using the WetNeph, the DryNeph, and the size distribution measurements (see Sect. 3.2 and the retrieval scheme in Fig. 1). The index of refraction was assumed to be that of $\left(\mathrm{NH}_{4}\right)_{2} \mathrm{SO}_{4}$ for the entire period, which is a reasonable guess as can be seen in Fig. 11 where the dry calculated versus measured values of $\sigma_{\mathrm{sp}}(\lambda=550 \mathrm{~nm})$ are shown. As mentioned above, neglecting the imaginary part is only possible because no strong absorbing aerosol was found during our period. The slope $s$ between calculated and measured scattering coefficient (see regression line in Fig. 11)

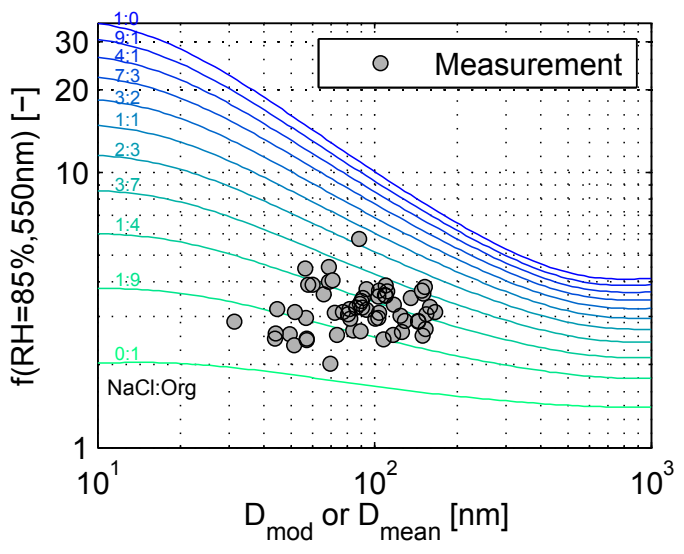

Fig. 9. Scattering enhancement $f(\mathrm{RH}=85 \%, \lambda=550 \mathrm{~nm})$ modeled for various $\mathrm{NaCl}$ to organic species volume ratios (colored lines) versus the mode diameter $D_{\text {mod }}$ of a log-normal size distribution (with a fixed geometric standard deviation of 1.8). The grey points depict the measured values of $f(\mathrm{RH}=85 \%, \lambda=550 \mathrm{~nm})$ versus the number mean diameter $D_{\text {mean }}$ measured by SMPS and OPC (daily averages).

would decrease accordingly if an imaginary part was included in the refractive index (e.g. with $m=1.53+0.001 \mathrm{i} \rightarrow$ $s=0.91$, with $m=1.53+0.01 \mathrm{i} \rightarrow s=0.82$ or with $m=1.53+0.1 \mathrm{i}$ $\rightarrow s=0.56)$. The growth factor $g(\mathrm{RH})$ was calculated in 2-h intervals and then averaged to daily values. Figure $7 \mathrm{e}$ reveals a higher retrieved $g(\mathrm{RH})$ during sea salt periods especially in the last third of the campaign. This is reasonable because sea salt is amongst the most hygroscopic atmospheric aerosol (Swietlicki et al., 2008). The rest of the measurement period could be dominated by secondary inorganic or organic aerosol, especially during the first half of the campaign, where $24 \mathrm{~h}$ of sunlight probably promoted secondary aerosol production. The scatter plot of $\kappa$ (calculated from $g(\mathrm{RH})$ at $\mathrm{RH}=85 \%$ using Eq. 2) versus $V_{\mathrm{OPC}} / V_{\text {tot }}$ shows again that the sea salt contribution has an influence on the magnitude of the hygroscopicity (see Fig. 8c). Campaign average and percentile values of $g(\mathrm{RH})$ (and its $\kappa$ value) are given in Table 1.

These findings confirm the hypothesis that compensating effects of hygroscopicity and size determined the temporal stability of $f(\mathrm{RH}=85 \%)$ at Zeppelin station during our campaign. While the beginning of the campaign (July and August) mainly was dominated by smaller and less hygroscopic particles, the end (September and October) was dominated by larger and more hygroscopic particles.

\subsection{Impact of $f(\mathrm{RH})$ on climate relevant parameters}

To demonstrate the impact of $f(\mathrm{RH})$ on properties which are important to estimate the radiative forcing of aerosol particles, the single scattering albedo $\omega_{0}$ was determined from the dry in-situ measurements as well as for the actual ambient 


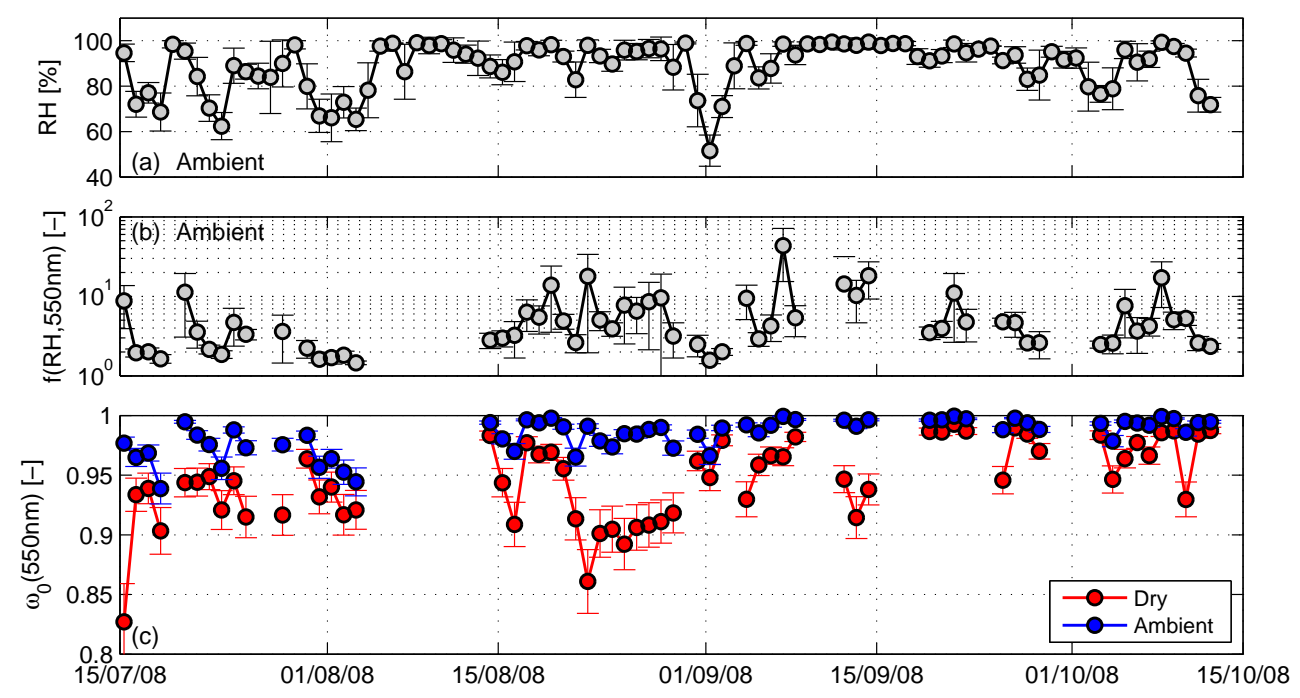

Fig. 10. Single scattering albedo of the measured dry aerosol and recalculated to ambient conditions. (a): Relative humidity (RH) outside Zeppelin station (error bars denote standard deviation of daily average). (b): Scattering enhancement factor $f(\mathrm{RH}, \lambda=550 \mathrm{~nm})$ at ambient RH. (c): Single scattering albedo $\omega_{0}(\lambda=550 \mathrm{~nm})$ measured at dry conditions (red points) and recalculated to ambient RH (blue points, daily averages, error bars are determined by error propagation).

RH. $\omega_{0}$ gives the fraction of the radiation attenuated by aerosol particles due to scattering. It is defined as the ratio of the aerosol scattering coefficient $\sigma_{\mathrm{sp}}$ to the total aerosol extinction coefficient, which is the sum of $\sigma_{\mathrm{sp}}$ and the absorption coefficient $\sigma_{\text {ap }}$ :

$\omega_{0}^{\mathrm{dry}}=\frac{\sigma_{\mathrm{sp}}}{\sigma_{\mathrm{sp}}+\sigma_{\mathrm{ap}}}$.

All variables are dependent on the wavelength $\lambda$, which is omitted in Eq. (10) for simplicity reasons. $\omega_{0}$ is here determined by the (dry) in-situ measurements of $\sigma_{\mathrm{sp}}$ (DryNeph) and $\sigma_{\text {ap }}$ (aethalometer, using Eq. 4). Since the aethalometer measures at different wavelengths than the nephelometer, the absorption coefficients were recalculated to the wavelengths of the nephelometer using the Ångström law:

$\sigma_{\mathrm{ap}}(\lambda)=\beta \lambda^{-\alpha}$,

where $\lambda$ is the wavelength of the aethalometer, $\beta$ a concentration dependent constant and $\alpha$ the Ångström exponent. Equation 11 was fitted to the averaged spectra of the aethalometer measurement (using all available channels) to retrieve $\beta$ and $\alpha$, which then allowed to calculate the absorption coefficient at the individual nephelometer wavelength.

To retrieve the real ambient value of $\omega_{0}$ - from now on called $\omega_{0}^{\mathrm{amb}}$ - the daily average of the RH measured outside of the Zeppelin station is used (see Fig. 10a, error bars denote the standard deviation). Using the ambient $\mathrm{RH}$, the daily value of $\gamma_{>75 \%}$ (see Fig. 7a) and Eq. (8) is used to calculate the ambient $f(\mathrm{RH})$ (see Fig. 10b, for $\lambda=550 \mathrm{~nm}$ ). The outliers in Fig. 10b with $f(\mathrm{RH})$ values above 20-30 are on the one hand the result of the large uncertainties in $\gamma_{>75 \%}$ on days which were characterized by extremely low concentrations. On the other hand, values at high $\mathrm{RH}>95 \%$ have to be treated with care, because small uncertainties in the ambient $\mathrm{RH}$ measurement have a strong impact on the determined $f(\mathrm{RH})$ (e.g. $f(\mathrm{RH}) \rightarrow \infty$ for $\mathrm{RH} \rightarrow 100 \%$ in Eq. 8).

The ambient single scattering albedo $\omega_{0}^{\text {amb }}$ is then calculated as followed:

$\omega_{0}^{\mathrm{amb}}=\frac{f(\mathrm{RH}) \sigma_{\mathrm{sp}}}{f(\mathrm{RH}) \sigma_{\mathrm{sp}}+\sigma_{\mathrm{ap}}}$.

The absorption coefficient $\sigma_{\text {ap }}$ is assumed not to change in a significant way with increasing $\mathrm{RH}$, which is a reasonable assumption for the Arctic aerosol. Nessler et al. (2005b) e.g. showed in a model study the insignificance of the absorption enhancement for an aerosol with high values of $\omega_{0}$ (here for the free tropospheric aerosol found at the JFJ).

The dry and ambient values of $\omega_{0}$ are seen in Fig. 10c (the error bars were calculated by Gaussian error propagation using the standard deviation of $\mathrm{RH}$, assuming a $10 \%$ uncertainty of the nephelometer (Anderson et al., 1996), a 20\% uncertainty of the aethalometer (M. Collaud, MeteoSwiss, Payerne, personal communication, 2010) and the error of the $\gamma_{>75 \%}$ coefficient, which is the difference of the $95 \%$ confidence level). The dry in-situ measured values of $\omega_{0}^{\text {dry }}$ are already close to one (mean $\omega_{0}^{\text {dry }}=0.95$, 90th percentile $\omega_{0}^{\text {dry }}=0.99$ ), which means that most of the light extinction by aerosol particles is caused by scattering. In the high humidity ambient environment, the $\omega_{0}^{\mathrm{amb}}$ increases to values even closer to one (mean $\omega_{0}^{\mathrm{amb}}=0.98$, 90th percentile $\omega_{0}^{\mathrm{amb}}=0.997$ ). For some days the difference between the dry and the ambient $\omega_{0}$ is quite large. Such cases could be 


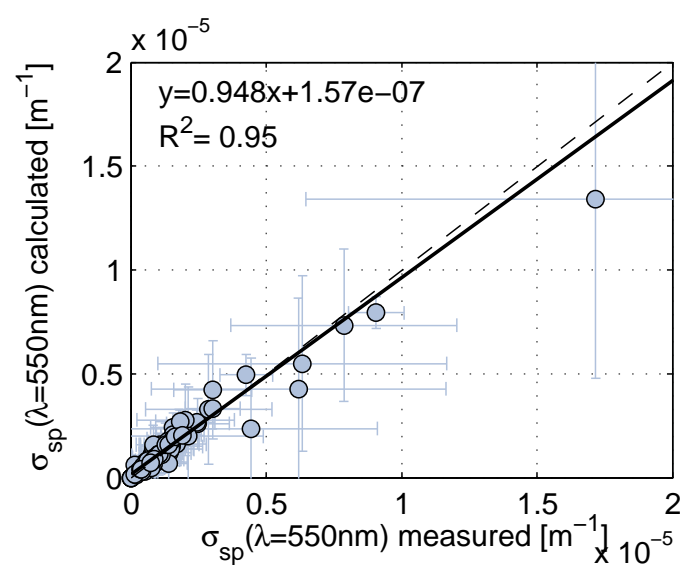

Fig. 11. Dry calculated versus dry measured scattering coefficients (at $\lambda=550 \mathrm{~nm}$ ) using a refractive index of $\left(\mathrm{NH}_{4}\right)_{2} \mathrm{SO}_{4}$ for the entire campaign and the measured dry size distribution (daily averages, error bars denote standard deviation of the calculated and measured one-hour values). A weighted linear least-square regression is added to the plot (black line).

important for the critical single scattering albedo (Haywood and Shine, 1995), which is a threshold of $\omega_{0}$ that determines whether the radiative forcing will be a negative (cooling) or a positive (warming) one. Over a high albedo surface there are cases where using $\omega_{0}^{\text {dry }}$ can cause opposite signs in the radiative forcing than if $\omega_{0}^{\text {wet }}$ was used (Randles et al., 2004).

\subsection{Predicting $f(\mathbf{R H})$}

The humidograms in Fig. 6 and the time lines in Fig. 7 already demonstrated through their relatively high values of $f(\mathrm{RH})$ the need to correct the dry in-situ measured scattering coefficients. The ambient RH during our investigated time period is characterized by high values ( $\mathrm{RH}$ mean: $89.0 \%$, 10th percentile: $70.3 \%$, 90th percentile: $99.3 \%$, see Fig. 10a), which in addition shows the need to account for hygroscopic growth. Recommendations will be given in this section on how to transform dry measured scattering coefficients to ambient conditions. This is only valid for Arctic aerosol similar to the one found at Zeppelin station during summer and fall.

The model calculations to predict $f(\mathrm{RH})$ measured by the WetNeph were repeated with modified input parameters. As input, daily averages of the measured dry number size distribution and a constant dry refractive index of $\left(\mathrm{NH}_{4}\right)_{2} \mathrm{SO}_{4}$ were used. The calculations were done for a larger $\mathrm{RH}$ range of $\mathrm{RH}=75-95 \%$. The RH dependency of $g(\mathrm{RH})$ was accounted for by using the $\kappa$ model (Eq. 2). Different $\kappa$ values of the hygroscopic growth were used to test the sensitivity of $f(\mathrm{RH})$ to hygroscopicity. The calculations were performed for $\kappa=1.11,0.57$, and 0.24 , corresponding to the maximum, mean and minimum retrieved hygroscopic growth factor, re-

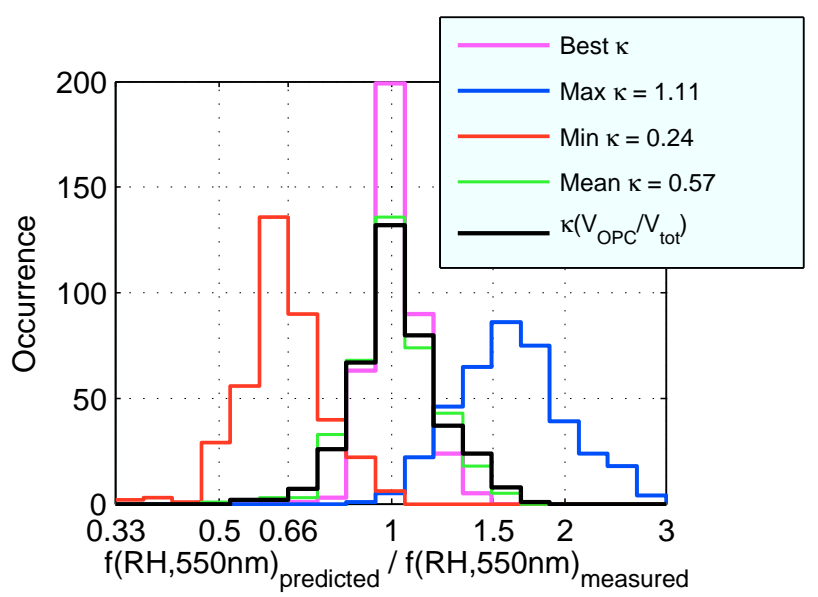

Fig. 12. Histogram of predicted to measured $f(\mathrm{RH}, \lambda=550 \mathrm{~nm})$ within $\mathrm{RH}=75-95 \%$ using the minimum $(\kappa=0.24$, red line), the maximum ( $\kappa=1.11$, blue line), and the mean ( $\kappa=0.57$, green line) $\kappa$ obtained from the backward calculations as well as $\kappa$ as a function of the volume fraction of large particles $V_{\mathrm{OPC}} / V_{\text {tot }}$ (black line). Using the exact daily mean $\kappa$ derived from the backward calculation is also shown for comparison (magenta line).

spectively. In addition, $\kappa$ was parameterized as a function of $V_{\mathrm{OPC}} / V_{\mathrm{tot}}$, our proxy for sea salt contribution. Regression of the data shown in Fig. 8c gives the linear relationship:

$\kappa=0.28 \frac{V_{\mathrm{OPC}}}{V_{\mathrm{tot}}}+0.43$.

A comparison of the dry calculated scattering coefficients (daily averages) for the entire measurement period showed a good agreement with the measured values (see Fig. 11). Therefore, a fixed dry refractive index could be used here. Figure 12 shows the result as a histogram of the ratio of predicted to measured $f(\mathrm{RH})$. For comparison, the calculations were also done with the exact daily mean $\kappa$ (see magenta line in Fig. 12). Both using the maximum or minimum $\kappa$ causes a clear over- or under-prediction of $f(\mathrm{RH})$ by a factor of $\sim 1.7$ or $\sim 0.6$, respectively. Expressing $\kappa$ as a function of $V_{\mathrm{OPC}} / V_{\text {tot }}$ generally gives a better performance with the prediction ratios centered around 1 . However, just taking the campaign mean $\kappa \sim 0.57$ is already sufficient, when predicting $f(\mathrm{RH})$. Pure $\left(\mathrm{NH}_{4}\right)_{2} \mathrm{SO}_{4}$ has a $\kappa$ value of 0.48 at $\mathrm{RH}=85 \%$ (Topping et al., 2005), thereby explaining the good agreement between the measurement and the prediction for pure $\left(\mathrm{NH}_{4}\right)_{2} \mathrm{SO}_{4}$ as already shown in Fig. 7 d.

\section{Conclusions}

High scattering enhancement factors $f(\mathrm{RH}, \lambda=550 \mathrm{~nm})$ (mean \pm standard deviation $=3.24 \pm 0.63$ at $\mathrm{RH}=85 \%$ ) were observed during summer and fall 2008 at the Zeppelin station in Ny-Ålesund, Svalbard. No clear wavelength dependency of $f(\mathrm{RH})$ was found. The measured RH dependency 
of $f(\mathrm{RH})$ at $\mathrm{RH}$ between $75 \%$ and $95 \%$ can be well described by an empirical one-parameter equation. Filter measurements and FLEXPART simulations revealed considerable influence from sea salt aerosol during about one third of the time, also reflected in an enhanced volume fraction of large particles. Distinct deliquescence was frequently observed during sea salt influenced periods, while water uptake on the hydration branch was gradual during the other periods. No distinct or even a slightly negative correlation was found between sea salt influence and $f(\mathrm{RH})$ at $\mathrm{RH}=85 \%$. This is explained by the fact that equal diameter growth factors translate into smaller $f(\mathrm{RH})$ at bigger dry sizes. The mean dry size was indeed larger during sea salt influence, and reverse Mie calculations indicate that hygroscopic diameter growth factors were actually slightly higher than during periods without sea salt influence. However, variations of the inferred hygroscopic growth were rather small, such that assuming a constant mean hygroscopicity of $\kappa=0.57$ for the entire campaign introduces little additional uncertainty in model predictions of $f(\mathrm{RH})$ based on size distribution data. Although these results were obtained specifically for the Zeppelin station, they might as well be valid for other Arctic areas during summer and fall periods without the clear influence of anthropogenic pollution. In any case it is desirable to perform further measurements during other periods and other places in the Arctic.

It is important to include $f(\mathrm{RH})$ when deriving aerosol forcing properties like the single scattering albedo $\omega_{0}$ at ambient conditions. These results will be used in a future study to compare the in-situ measured scattering coefficients (now brought to ambient conditions) at the height of the Zeppelin station (at $475 \mathrm{~m}$ ) with lidar measurements, which are regularly performed from the town of $\mathrm{Ny}$-Ålesund located at sea level.

Acknowledgements. We thank Ove Hermansen and Jan Wasseng (Norwegian Institute for Air Research, NILU) and as well Dorothea Schulze and Trond Svenøe (Norwegian Polar Institute) for their support at the Zeppelin station. Thanks to the Stockholm University for performing the continuous aerosol observation at the Zeppelin station and the Swedish Environmental Protection Agency for its funding. We also thank NILU for providing the meteorological data from Zeppelin and the webcam pictures. This work was financially supported by the EC-projects: Global Earth Observation and Monitoring (GEOmon, contract 036677), European Supersites for Atmospheric Aerosol Research (EUSAAR, contract 026140), and the European Centre for Arctic Environmental Research (ARCFAC, contract 026129).

Edited by: L. M. Russell

\section{References}

Anderson, T., Covert, D., Marshall, S., Laucks, M., Charlson, R., Waggoner, A., Ogren, J., Caldow, R., Holm, R., Quant, F., Sem, G., Wiedensohler, A., Ahlquist, N., and Bates, T.: Performance characteristics of a high-sensitivity, three-wavelength, total scatter/backscatter nephelometer, J. Atmos. Ocean. Tech., 13, 967-986, 1996.

Anderson, T. L. and Ogren, J. A.: Determining aerosol radiative properties using the TSI 3563 integrating nephelometer, Aerosol Sci. Tech., 29, 57-69, 1998.

Bodhaine, B. A.: Barrow surface aerosol: 1976-1986, Atmos. Environ., 23(11), 2357-2369, 1989.

Bohren, C. and Huffmann, D.: Absorption and Scattering of Light by Small Particles, Wiley-VCH, New York, USA, 2004.

Carrico, C. M., Kus, P., Rood, M. J., Quinn, P. K., and Bates, T. S.: Mixtures of pollution, dust, sea salt, and volcanic aerosol during ACE-Asia: radiative properties as a function of relative humidity, J. Geophys. Res., 108(D23), 8650, doi:10.1029/2003JD003405, 2003.

Collaud Coen, M., Weingartner, E., Apituley, A., Ceburnis, D., Fierz-Schmidhauser, R., Flentje, H., Henzing, J. S., Jennings, S. G., Moerman, M., Petzold, A., Schmid, O., and Baltensperger, U.: Minimizing light absorption measurement artifacts of the Aethalometer: evaluation of five correction algorithms, Atmos. Meas. Tech., 3, 457-474, 2010, http://www.atmos-meas-tech.net/3/457/2010/.

Eleftheriadis, K., Vratolis, S., and Nyeki, S.: Aerosol black carbon in the European Arctic: measurements at Zeppelin station, Ny-Ålesund, Svalbard from 1998-2007, Geophys. Res. Lett., 36, L02809, doi:10.1029/2008GL035741, 2009.

EMEP: Manual for sampling and chemical analysis, Kjeller, Norwegian Institute for Air Research, EMEP/CCC Report 1/95, Last rev. 2006, 1995.

Fierz-Schmidhauser, R., Zieger, P., Wehrle, G., Jefferson, A., Ogren, J. A., Baltensperger, U., and Weingartner, E.: Measurement of relative humidity dependent light scattering of aerosols, Atmos. Meas. Tech., 3, 39-50, 2010a, http://www.atmos-meas-tech.net/3/39/2010/.

Fierz-Schmidhauser, R., Zieger, P., Gysel, M., Kammermann, L., DeCarlo, P. F., Baltensperger, U., and Weingartner, E.: Measured and predicted aerosol light scattering enhancement factors at the high alpine site Jungfraujoch, Atmos. Chem. Phys., 10, 23192333, 2010b, http://www.atmos-chem-phys.net/10/2319/2010/.

Fitzgerald, J. W., Hoppel, W. A., and Vietti, M. A.: The size and scattering coefficient of urban aerosol particles at Washington, DC as a function of relative humidity, J. Atmos. Sci., 39, 1838$1852,1982$.

Gassó, S., Hegg, D. A., Covert, D. S., Collins, D., Noone, K. J., Öström, E., Schmid, B., Russell, P. B., Livingston, J. M., Durkee, P. A., and Jonsson, H.: Influence of humidity on the aerosol scattering coefficient and its effect on the upwelling radiance during ACE2, Tellus B, 53, 546-567, 2000.

Gong, S. L.: A parameterization of sea salt aerosol source function for sub- and super-micron particles, Global Biogeochem. Cy., 17, 1097, doi:10.1029/2003GB002079, 2003.

Hale, G. M. and Querry, M. R.: Optical constants of water in the 200-nm to 200- $\mu$ m wavelength region, Appl. Optics, 12(3), 555563, 1973. 
Haywood, J. M. and Shine, K. P.: The effect of anthropogenic sulfate and soot aerosol on the clear sky planetary radiation budget, Geophys. Res. Lett., 22(5), 603-606, 1995.

Kasten, F.: Visibility in the phase of precondensation, Tellus, 21, 631-635, 1968.

Köehler, H.: The nucleus and growth of hygroscopic droplets, T. Faraday Soc., 32, 1152-1161, 1936.

Kotchenruther, R. A. and Hobbs, P. V.: Humidification factors of aerosols from biomass burning in Brazil, J. Geophys. Res., 103(D24), 32081-32089, 1998.

Ming, Y. and Russell, L.: Predicted hygroscopic growth of sea salt aerosol, J. Geophys. Res., 106(D22), 28259-28274, 2001.

Nessler, R., Weingartner, E., and Baltensperger, U.: Adaptation of dry nephelometer measurements to ambient conditions at the Jungfraujoch, Environ. Sci. Technol., 39, 2219-2228, 2005a.

Nessler, R., Weingartner, E., and Baltensperger, U.: Effect of humidity on aerosol light absorption and its implications for extinction and the single scattering albedo illustrated for a site in the lower free troposphere, J. Aerosol Sci., 36, 958-972, $2005 \mathrm{~b}$.

Petters, M. D. and Kreidenweis, S. M.: A single parameter representation of hygroscopic growth and cloud condensation nucleus activity, Atmos. Chem. Phys., 7, 1961-1971, 2007, http://www.atmos-chem-phys.net/7/1961/2007/.

Quinn, P. K., Miller, T. L., Bates, T. S., Ogren, J. A., Andrews, E., and Shaw, G. E.: A 3-year record of simultaneously measured aerosol chemical and optical properties at Barrow, Alaska, J. Geophys. Res, 107(D11), 4130, doi:10.1029/2001JD001248, 2002.

Randles, C. A., Russell, L. M., and Ramaswamy, V.: Hygroscopic and optical properties of organic sea salt aerosol and consequences for climate forcing, Geophys. Res. Lett., 31, L16108, doi:10.1029/2004GL020628, 2004.

Sheridan, P. J., Delene, D. J., and Ogren, J. A.: Four years of continuous surface aerosol measurements from the Department of Energy's Atmospheric Radiation Program Southern Great Plains Cloud and Radiation Testbed site, J. Geophys. Res., 106, 2073520747, 2001.

Sjogren, S., Gysel, M., Weingartner, E., Alfarra, M. R., Duplissy, J., Cozic, J., Crosier, J., Coe, H., and Baltensperger, U.: Hygroscopicity of the submicrometer aerosol at the high-alpine site Jungfraujoch, $3580 \mathrm{~m}$ a.s.1., Switzerland, Atmos. Chem. Phys., 8, 5715-5729, 2008, http://www.atmos-chem-phys.net/8/5715/2008/.

Stohl, A., Forster, C., Frank, A., Seibert, P., and Wotawa, G.: Technical note: The Lagrangian particle dispersion model FLEXPART version 6.2, Atmos. Chem. Phys., 5, 2461-2474, 2005, http://www.atmos-chem-phys.net/5/2461/2005/.
Ström, J., Umegård, J., Tørseth, K., Tunved, P., Hansson, H.-C., Holmén, K., Wismann, V., Herber, A., and König-Langlo, G.: One year of particle size distribution and aerosol chemical composition measurements at the Zeppelin Station, Svalbard, Mar 2000-Mar 2001, Phys. Chem. Earth Pt. A/B/C, 28(28-32), 1181-1190, 2003.

Swietlicki, E., Hansson, H.-C., Hämeri, K., Svenningsson, B., Massling, A., McFiggans, G., McMurry, P. H., Petäjä, T., Tunved, P., Gysel, M., Topping, D., Weingartner, E., Baltensperger, U., Rissler, J., Wiedensohler, A., and Kulmala, M.: Hygroscopic properties of submicrometer atmospheric aerosol particles measured with H-TDMA instruments in various environments - a review, Tellus B, 60, 432-469, 2008.

Toon, O. B., Pollack, J. B., and Khare, B. N.: Optical-constants of several atmospheric aerosol species - ammonium-sulfate, aluminium-oxide, and sodium-chloride, J. Geophys. Res., 81(33), 5733-5748, 1976.

Topping, D. O., McFiggans, G. B., and Coe, H.: A curved multicomponent aerosol hygroscopicity model framework: Part 2 Including organic compounds, Atmos. Chem. Phys., 5, 1223 1242, 2005, http://www.atmos-chem-phys.net/5/1223/2005/.

Wang, W., Rood, M. J., Carrico, C. M., Covert, D. S., Quinn, P. K., and Bates, T. S.: Aerosol optical properties along the northeast coast of North America during the New England Air Quality Study - Intercontinental Transport and Chemical Transformation 2004 campaign and the influence of aerosol composition, J. Geophys. Res., 112, D10S23, doi:10.1029/2006JD007579, 2007.

Weingartner, E., Saathoff, H., Schnaiter, M., Streit, N., Bitnar, B., and Baltensperger, U.: Absorption of light by soot particles: determination of the absorption coefficient by means of aethalometers, J. Aerosol Sci., 34, 1445-1465, 2003.

WMO/GAW: Aerosol Measurement Procedures Guidelines and Recommendations, GAW Report No. 153, World Meteorological Organization Global Atmosphere Watch, Geneva, Switzerland, 2003.

Yan, P., Pan, X. L., Tang, J., Zhou, X. J., Zhang, R. J., and Zeng, L. M.: Hygroscopic growth of aerosol scattering coefficient: a comparative analysis between urban and suburban sites at winter in Beijing, Particuology, 7, 52-60, 2009.

Yang, X., Pyle, J. A., and Cox, R. A., Sea salt aerosol production and bromine release: Role of snow on sea ice, Geophys. Res. Lett., 35, L16815, doi:10.1029/2008GL034536, 2008. 